Received: 27 September 2018

Accepted: 29 January 2019

Published online: 29 May 2019

\section{OPEN Transcriptomics Analysis Reveals New Insights into the Roles of Notch1 Signaling on Macrophage Polarization}

\author{
Chetan P. Hans $\mathbb{D}^{1,2,3}$, Neekun Sharma ${ }^{1,3}$, Sidharth Sen $\mathbb{D}^{4}{ }^{4}$, Shuai Zeng ${ }^{5}$, Rishabh Dev ${ }^{1,3}$, \\ Yuexu Jiang ${ }^{5}$, Advitiya Mahajan ${ }^{1} \&$ Trupti Joshi $^{4,5,6,7}$
}

Naïve macrophages $(\mathrm{M} \varphi)$ polarize in response to various environmental cues to a spectrum of cells that have distinct biological functions. The extreme ends of the spectrum are classified as M1 and M2 macrophages. Previously, we demonstrated that Notch1 deficiency promotes Tgf- $\beta 2$ dependent M2-polarization in a mouse model of abdominal aortic aneurysm. The present studies aimed to characterize the unique set of genes regulated by Notch1 signaling in macrophage polarization. Bone marrow derived macrophages isolated from WT or Notch1 ${ }^{+1-}$ mice $(n=12)$ were differentiated to $\mathrm{M} \varphi, \mathrm{M} 1$ or M2-phenotypes by $24 \mathrm{~h}$ exposure to vehicle, LPS/IFN- $\gamma$ or IL4/IL13 respectively and total RNA was subjected to RNA-Sequencing $(n=3)$. Bioinformatics analyses demonstrated that Notch1 haploinsufficiency downregulated the expression of 262 genes at baseline level, 307 genes with LPS/ IFN- $\gamma$ and 254 genes with IL4/IL13 treatment. Among these, the most unique genes downregulated by Notch1 haploinsufficiency included fibromodulin (Fmod), caspase-4, Has1, Col1a1, Alpl and Igf. Pathway analysis demonstrated that extracellular matrix, macrophage polarization and osteogenesis were the major pathways affected by Notch1 haploinsufficiency. Gain and loss-of-function studies established a strong correlation between Notch1 haploinsufficiency and Fmod in regulating Tgf- $\beta$ signaling. Collectively, our studies suggest that Notch1 haploinsufficiency increases M2 polarization through these newly identified genes.

Vascular diseases including abdominal aortic aneurysm (AAA), atherosclerosis, obesity and cancer present a group of highly prevalent chronic conditions that share common inflammatory pathways ${ }^{1}$. These diseases are characterized by acute or chronic inflammation that can affect a specific organ or the whole system ${ }^{2-4}$. The onset of inflammation in these conditions correlates with an alteration in the dynamic balance of pro-inflammatory vs. anti-inflammatory macrophages that play a decisive role in the initiation and perpetuation of disease $\mathrm{s}^{5-7}$. Given their critical roles in disease pathogenesis, an understanding of the key factors that modulate macrophage differentiation may have tremendous therapeutic potential.

Naïve macrophages $(\mathrm{M} \varphi)$, in response to the local milieu, differentiates towards a variety of polarized states with distinct functions ${ }^{5}$. The extreme ends of this spectrum of polarization are referred to as either pro-inflammatory (M1) or immune-regulatory (M2) macrophages. These macrophage populations are heterogeneous and opposing in terms of expression of surface markers and functions ${ }^{5}$. In response to a local injury, M1-polarized macrophages induce pro-inflammatory cytokines and chemokines ${ }^{8,9}$. The M2-phenotype on the contrary, diminishes the inflammatory response, promotes tissue repair and healing via production of collagen and elastin precursors ${ }^{10}$. Although, there have been extensive studies on the pro-inflammatory and anti-inflammatory cytokines associated with M1 or M2-macrophages, the key factors that modulate M1/M2

${ }^{1}$ Department of Cardiovascular Medicine, University of Missouri, Columbia, USA. ${ }^{2}$ Medical Pharmacology and Physiology, University of Missouri, Columbia, USA. ${ }^{3}$ Dalton Cardiovascular Research Center, University of Missouri, Columbia, USA. ${ }^{4} \mathrm{MU}$ Informatics Institute, University of Missouri, Columbia, USA. ${ }^{5}$ Department of Electrical Engineering and Computer Science, University of Missouri, Columbia, USA. ${ }^{6}$ Department of Health Management and Informatics, School of Medicine, University of Missouri, Columbia, USA. ${ }^{7}$ Christopher S. Bond Life Science Center, University of Missouri, Columbia, USA. Correspondence and requests for materials should be addressed to C.P.H. (email: HansCP@health.missouri.edu) 
polarization have not been well-documented ${ }^{11-14}$. Recent studies have further sub-classified M2 macrophages into M2a, M2b, M2c or tumor-associated (TAMs) subsets depending upon the external stimulus and transcriptional changes ${ }^{12,15,16}$. Thus, the mechanism of macrophage polarization is exceedingly becoming complex and high-throughput studies are required to identify the key regulators for such polarization ${ }^{13}$.

We, and others, have shown that Notch1 signaling plays a causal role in M1/M2 differentiation during the development of several vascular pathologies ${ }^{17-24}$. The Notch signaling pathway consists of a family of four Notch receptors (1-4). Interactions with the Jagged and Delta ligand families results in the release and translocation of the Notch1 intracellular domain (NICD) into the nucleus where it binds and associates with the transcription factor Cp-binding factor-1 (CBF1; also known as Rbp-J $\kappa$ or Csl ${ }^{25-27}$. Although, the current findings suggest a possible link between Notch activation and an inflammatory environment in many disease states, the possible interplay between Notch 1 signaling and inflammation in the context of macrophage polarization is poorly studied $^{18-20,24,28,29}$. We previously reported that inhibition of Notch signaling attenuates the progression of AAA at early stages by reducing the inflammatory response associated with a Tgf- $\beta 2$ dependent increase in differentiation of M2-macrophages ${ }^{20,21}$. However, the molecular mechanism by which Notch1 signaling regulates macrophage polarization is unknown.

Using RNA sequencing (RNA-Seq), we aimed to: i) determine putative markers specific for M1 and M2 polarization and ii) analyze differentially expressed genes (DEGs) which are unique to Notch1 haploinsufficiency. Our data revealed that Notch 1 haploinsufficiency decreases the expression of fibromodulin (Fmod), a cytosolic protein implicated in the M2-polarization of macrophages.

\section{Results}

Hierarchal clustering, correlation matrix and gene module prediction. The aim of the study was to determine the effect of Notch1 haploinsufficiency on expression of genes that are unique to M1 or M2 phenotype, using the unbiased RNA-Seq approach. Bone marrow derived macrophages (BMDMs) were stimulated with lipopolysaccharide (LPS; $100 \mathrm{ng} / \mathrm{ml})$ and interferon- $\gamma($ IFN- $\gamma ; 20 \mathrm{ng} / \mathrm{ml})$ or IL-4/IL-13 (10 ng/ml each) for $24 \mathrm{~h}$ to polarize into M1 or M2 phenotype respectively. Reads per kilobase of transcript, per million mapped reads (RPKM) data for detectable mouse genes ( $>$ RQT in at least one sample) was used for hierarchical clustering analysis by Cluster 3.0 software $^{30}$. Genes were median centered prior to hierarchical clustering and analysis was conducted using centered correlation as the similarity metric and average linkage as the clustering method (Fig. 1A). Heat maps of all the expressed genes demonstrated that the naïve macrophages $(\mathrm{M} \varphi)$, LPS/IFN- $\gamma$ treated or IL4/IL13 treated BMDMs from WT mice clustered most closely with respective treatments to the Notch $1^{+/-}$BMDMs (Fig. 1A). LPS/ IFN- $\gamma$ treated macrophages clustered farthest away from the IL4/IL13 treated macrophages suggesting that these stimulants had different and contrasting effects. Pearson's correlation coefficient analysis for all 18 samples showed strong correlation between $W T$ and Notch $1^{+-}$BMDMs at baseline levels or with similar treatments (Fig. 1B).

Gene co-expression networks were determined using weighted correlation network analysis (WGCNA) ${ }^{31}$, to compute and visualize the correlation among a list of differentially expressed genes (Fig. 1C and Table 1). WGCNA gene module analysis on combined differential gene list for WT and Notch $1^{+/-}$datasets for all three conditions predicted 7 gene modules (Fig. 1C). The different gene modules have 35 (red), 83 (brown), 93 (blue), 8 (grey), 39 (green), 100 (turquoise) and 41 (yellow) genes in each module. For the brown module, the predicted pathways having at least 3 mapped genes included metabolic, Ras and Rap1 signaling pathways. For the blue module, the predicted pathways included PI3K-Akt signaling, focal adhesions, ECM-receptor interactions and cell adhesion molecules. For the green module, pathways included calcium signaling, oocyte meiosis, and the dopaminergic synapse. For the turquoise module, cell adhesion molecules (CAMs), PI3K-Akt signaling, leukocyte trans-endothelial migration, Rap1 signaling, antigen processing and presentation pathways were implicated with more than 3 genes mapped. The yellow module had more than three genes mapped to metabolic pathways, ECM-receptor interactions and proteoglycans in cancer. Red and grey modules did not have genes that have known pathway mappings. Using KBCommons database and in-house novel algorithm, we performed a step-wise active pathway detection using a dynamic programming approach. The results are represented as tree structures showing the summarized networks for the control, LPS/IFN- $\gamma$ and IL4/IL13 treatments respectively with Notch1 as the root of the tree (Supplemental Fig. 1A-C). Among these three tree comparisons as shown in Venn diagram (Supplemental Fig. 1D) 12 genes were common to all of them (Myc, Fgr, Ptk2, Pik3cb, Rbpjl, Hspa8, Hkdc1, Glb1, Vegfc, Akt3, Mmp9 and Notch1). There are 14 additional genes common between the control and LPS/IFN- $\gamma$ tree (Ldha, Prkcd, Mmp14, Ngfr, Pkm, Eif4ebp2, Mapk3, Dlat, Pdhb, Mtor, Mapk12, St3gal2, St6galnac6, and Plau), while 7 genes common between LPS/IFN- $\gamma$ and IL4/IL13 (Apaf1, Casp4, Sdc1, Itgb3, Col1a2, Trp53, and Col1a1). There were 6 common genes between Control and IL4/IL13 treatment (Pdpk1, Foxo3, B4galt2, B3galt1 and St3gal4, and Mmp2). Control has 45 and LPS/IFN- $\gamma$ has 58 unique genes in the tree, while IL4/IL13 tree has 53 unique genes as shown (Supplemental Fig. 2D). The visualization of these graphical data matrix depict that the variance in the data set are primarily driven by different treatments and the divergence of the pattern of these data seems to be characteristic for each sample group.

Principal Component Analysis (PCA) was performed on the RPKM data for 17,400 low p-value (minimum ANOVA $p<0.05)$ mouse genes. The RPKM values were log 10 -transformed, centered so that each sample had mean 0 , and the first three principal components were calculated (Supplemental Fig. 2). To find genes that substantially contribute to each PCA value, the correlation and fold-change in expression of each gene with the first three principal components was calculated according to the methods of Sharov et al. ${ }^{32}$. Genes with a positive or negative correlation of at least 0.9 and a fold change of at least 2.0 compared with the principal components are reported (Supplemental Fig. 2). The close clustering of the groups with similar treatment as revealed by PCA suggests relatedness of samples and that the alterations in the expression of genes among the dataset can be attributed to variance induced by Notch1 haploinsufficiency, thus validating the approach. 


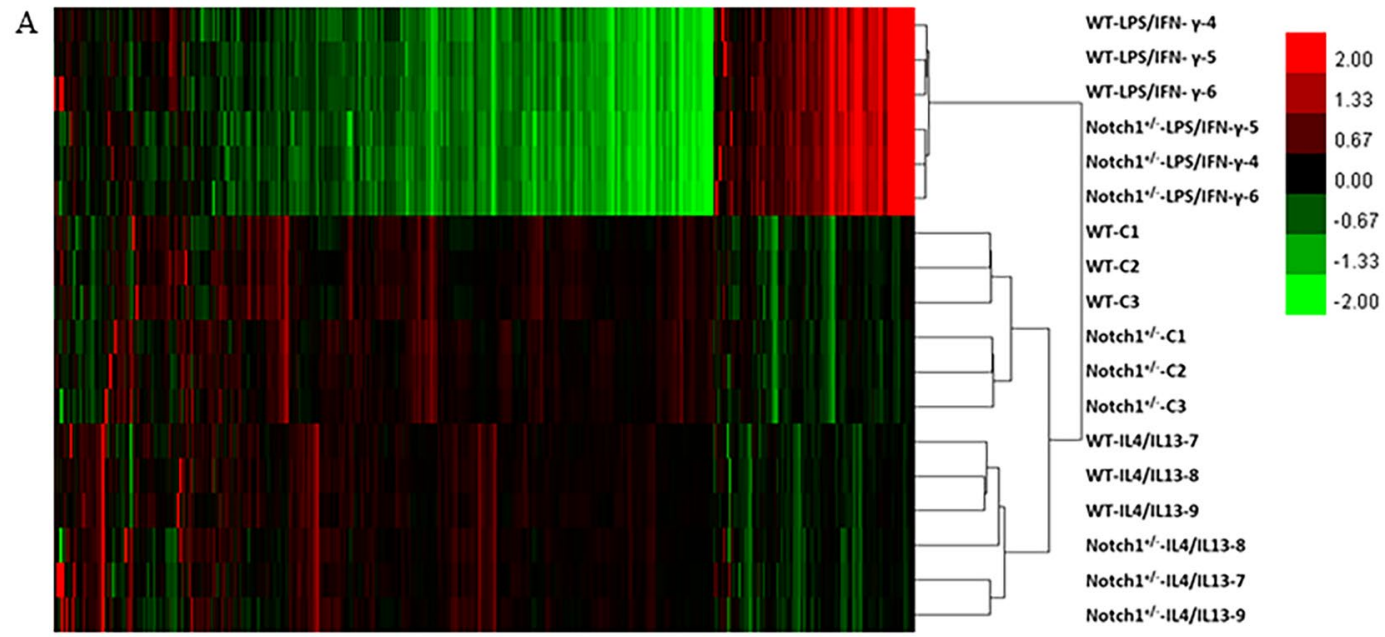

B

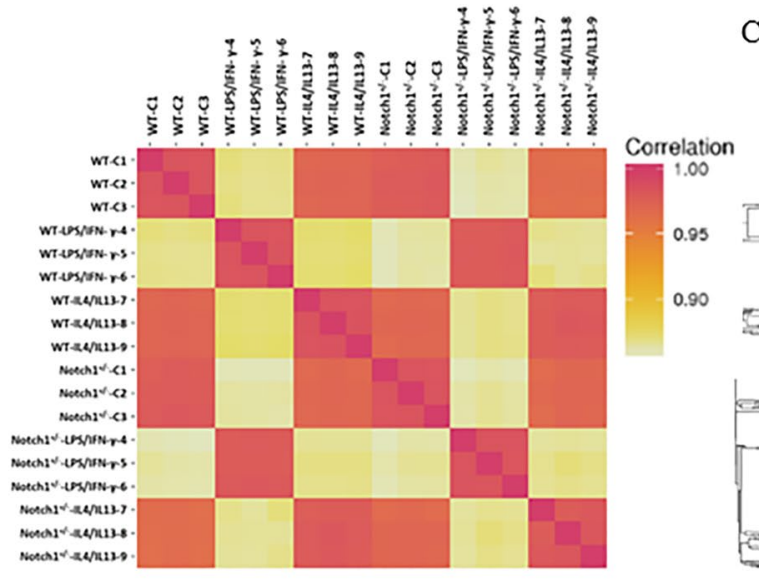

$\mathrm{C}$

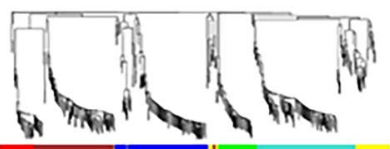

Figure 1. Data matrix analyses distributed the data into expected subgroups and treatments. (A) Heat map from 20,375 detectable mouse genes in WT and $\mathrm{Notch}^{+/-}$BMDMs treated with vehicle, LPS/IFN- $\gamma$ or IL4/IL13. Reads per kilobase of transcript per million (RPKM) were $\log ^{2}$-transformed and loaded into Gene Cluster 3.0. Each colorbar unit represents a difference of one $\log ^{2}$ unit in RPKM. The green and red color indicates downregulation and upregulation of the genes respectively and the intensity of the color corresponds to fold difference in the expression. (B) Pearson's correlation coefficient, calculated for all the 18 samples. (C) Weighted correlation network analysis (WGCNA) to visualize the correlation among the differentially expressed genes. The expression of genes with fold change value between -1 to 1 and q-value less than 0.05 were selected as inputs of WGCNA. The modules were constructed for this network by using hierarchical clustering. The genes with high correlation were clustered into different modules. With this threshold, the number of differential genes in Notch $1^{+/-} \mathrm{C}$ vs. WT-C, in Notch ${ }^{+/-}$IL4/ IL13 versus WT-IL4/IL13 and in Notch1 ${ }^{+/-}$LPS/IFN- $\gamma$ versus WT-LPS/IFN- $\gamma$, were 199, 155 and 158 respectively.

Notch1 haploinsufficiency differentially regulates novel M1/M2 genes at baseline. Notch1 haploinsufficiency downregulated the expression of 250 genes below $50 \%$ of the WT M $\varphi$ in the absence of external stimulant (Table 2; left green panel). Among this category, the prominent genes were hyaluronan synthase 1 (Has1), caspase 4 (Casp4), fibromodulin (Fmod), hairy/enhancer-of-split related with YRPW motif-like $($ HeyL), hairy and enhancer of split 1 (Hes 1), delta-like 4 (Dll4), collagen, type I, alpha 1 (Colla1), and insulin-like growth factor 2 (Igf2). Categorization of these genes to Gene Ontology (GO) $)^{33}$ and KEGG pathway ${ }^{34}$ revealed that common pathways affected by Notch1 haploinsufficiency at baseline levels include leukocyte trans-endothelial migration, cell adhesion molecules, ECM-receptor interactions, focal adhesion, cancer, RAS signaling, cAMP signaling, Rap1 signaling, Pi3k-Akt signaling and metabolic pathways (Table 2 and Fig. 2A).

Notch 1 haploinsufficiency also upregulated the baseline expression of $\sim 100$ genes by two-fold or more in the absence of external stimulants (Table 2; right red panel and data not shown). The genes relevant to macrophage polarization in this category included maltase-glucoamylase $(\mathrm{Mgam})$, guanine nucleotide binding protein 13 (Gng13), and $\gamma$-parvin (Parv- $\gamma$ ). The important pathways affected by the upregulation of these genes included cell cycle, chemokine signaling pathway and cancer (Fig. 2A and data not shown).

Notch1 haploinsufficiency dysregulates selective genes in response to LPS/IFN- $\gamma$ treatment. Wide-ranging effects of LPS/IFN- $\gamma$ were observed in $~ 2000$ genes with a cutoff of a two-fold increase. The top 100 genes robustly upregulated in response to LPS/IFN- $\gamma$ treatment ranged from hundreds to thousands fold relative 


\begin{tabular}{|c|c|c|c|c|c|c|c|c|}
\hline \multirow[b]{2}{*}{ Description } & \multirow[b]{2}{*}{$\begin{array}{l}\text { Total } \\
\text { Input IDs }\end{array}$} & \multirow[b]{2}{*}{$\begin{array}{l}\text { WebGestalt } \\
\text { Mapped IDs }\end{array}$} & \multirow[b]{2}{*}{$\begin{array}{l}\text { Unique } \\
\text { IDs }\end{array}$} & \multirow[b]{2}{*}{$\begin{array}{l}\text { KEGG } \\
\text { Results }\end{array}$} & \multirow[b]{2}{*}{$\begin{array}{l}\text { WIKI } \\
\text { Results }\end{array}$} & \multicolumn{3}{|c|}{ GO categories } \\
\hline & & & & & & $\begin{array}{l}\text { Biological } \\
\text { Process }\end{array}$ & \begin{tabular}{|l|} 
Molecular \\
Function
\end{tabular} & $\begin{array}{l}\text { Cellular } \\
\text { Component }\end{array}$ \\
\hline Reference Gene Set & 20375 & 12413 & 12410 & NA & & & & \\
\hline Notch $1^{+/-}$vs WT-C FC $>1.5 \mathrm{Up}$ & 260 & 148 & 148 & $\underline{4(4)}$ & $\underline{6(5)}$ & $\underline{40(40)}$ & $\underline{23(8)}$ & $\underline{33(25)}$ \\
\hline Notch $^{+/-}$vs WT-(C) FC > 1.5 Down & 433 & 383 & 383 & $9(8)$ & $\underline{13(11)}$ & $\underline{40(40)}$ & $\underline{40(40)}$ & $\underline{40(40)}$ \\
\hline Notch $1^{+/-}$vs WT (LPS/IFN- $\left.\gamma\right)$ FC $>1.5$ Up & 234 & 142 & 142 & $\underline{29(23)}$ & $\underline{12(11)}$ & $\underline{40(40)}$ & $\underline{40(30)}$ & $\underline{21(18)}$ \\
\hline Notch $^{+/-}$vsWT $($LPS/IFN- $\gamma)$ FC $>1.5$ Down & 763 & 599 & 599 & $\underline{8(8)}$ & $\underline{6(5)}$ & $\underline{40(40)}$ & $\underline{40(40)}$ & $\underline{40(40)}$ \\
\hline Notch $^{+/-}$vs WT (IL4/IL13) FC >1.5 Up & 99 & 48 & 48 & $\underline{4(2)}$ & $\underline{7(6)}$ & $\underline{40(40)}$ & $\underline{15(13)}$ & $\underline{12(12)}$ \\
\hline Notch1 $^{+/-}$vs WT (IL4/IL13) FC > 1.5 Down & 476 & 402 & 402 & $\underline{13(7)}$ & $\underline{5(2)}$ & $\underline{40(40)}$ & $\underline{40(40)}$ & $\underline{40(40)}$ \\
\hline
\end{tabular}

Table 1. Pathway Analysis Summary. Criteria selected based on the Tukey $p$ value $(<0.05)$ and Fold Change ( $>2$ up or down) for the specified comparison

to naïve $\mathrm{M} \varphi$ (Supplemental Table 1). Upregulation of M1-genes including, chemokine (C-X-C motif) ligand 9 (Cxcl9), nitric oxide synthase 2, inducible (Nos2), immunoresponsive gene 1 (Irg1), Cxcl10, interleukin 6 (Il6), $I l 12 b$, formyl peptide receptor 2 (Fpr2), tumor necrosis factor (Tnf), Fpr1 and Has1 was observed in WT BMDMs following LPS/IFN- $\gamma$ treatment relative to baseline levels. Comparable increase in the expression of these genes was also observed in Notch $1^{+/-}$BMDMs with LPS/IFN- $\gamma$ treatment but the extent of the increase was attenuated significantly in some genes including Cxcl9, Irg1, Cxcl10, Fpr2 and Has $1(P<0.01)$. Interestingly, we observed $50 \%$ or more reduction in the expression of $\sim 100$ genes with Notch1 haploinsufficiency in BMDMs treated with LPS/IFN- $\gamma$ compared to WT-BMDMs treated with LPS/IFN- $\gamma$ (Table 3; left green boxes). This category included colony stimulating factor 2 (Csf2), lymphocyte antigen 6 complex, locus G $(L y 6 g)$, interleukin 1 receptor-like 1 (Illr1), interleukin 2 receptor, beta chain (Il2rb), Has1, Casp4, lipopolysaccharide binding protein (Lbp) and Ccl19 genes which have potential associations with macrophage polarization.

In response to LPS/IFN- $\gamma$ treatment, downregulation of $\sim 4000$ genes below $50 \%$ of the baseline expression was observed in $W T$ and Notch $1^{+/-}$BMDMs (Supplemental Table 1). The important genes/families in this category were regulator of G-protein signaling 18 (Rgs18), brain expressed X-linked 1 and 4 (Bex1 and Bex4), CD28, peroxisome proliferator activated receptor gamma (Ppar- $\gamma)$, Il4, SRY-box 9 (Sox9), transforming growth factor beta 2 (Tgf- $\beta 2), M m p 8, M m p 12$, Tgf- $\beta$ receptor II (Tgf $\beta-R I I)$ and Tgf $\beta$-RI. Out of these 4000 genes, downregulated by LPS/IFN- $\gamma$, about 25 genes were significantly upregulated by Notch 1 haploinsufficiency (Table 3). Noticeable genes in this category include mannose receptor C1 (Mrc1), dehydrogenase/reductase member 9 (Dhrs9), Mmp8, Mmp12, Tlr8 and Lipn. The alteration in the expression of these genes with Notch1 haploinsufficiency suggests possible roles of Notch1 signaling in the macrophage polarization through these novel genes.

Notch1 haploinsufficiency dysregulates selective genes in response to IL4/IL-13 treatment. IL4/IL13 induced expression of distinct set of genes, which are known to play a significant role in the resolution of inflammation (Supplemental Table 2). This category included chitinase-like $($ Chil3,4,5,6), retinol binding protein 4 (Rbp4), IL13 receptor, alpha 2 (Il13ra2), Irf4, Arg1, suppressor of cytokine signaling 1 (Socs1), macrophage galactose $\mathrm{N}$-acetyl-galactosamine specific lectin $2(\mathrm{Mgl2})$ and $\mathrm{Ccl} 12$ genes. Notch 1 haploinsufficiency also increased the expression of these genes in response to IL4/IL13 and the magnitude of upregulation was even higher. Notch 1 haploinsufficiency also increased the expression of prolactin family members c2 and c3 (Prl2c2 and Prl2c3), small nucleolar RNA C/D box 32 A (Snord32a), small nucleolar RNA H/ACA box 74 A (Snora74a), osteoclast stimulatory transmembrane protein (Oc-stamp) and carbonic anhydrase 3 (Car3) significantly in response to IL4/IL13 treatment compared to WT BMDMs with similar regimen (Table 3).

IL4/IL13 treatment downregulated expression of $\sim 800$ genes to less than $50 \%$ of baseline expression in both WT and Notch $1^{+1-}$ mice (Supplemental Table 2). The genes in this category which may have potential roles in macrophage polarization were aldo-keto reductase family 1 ( $A k r 1 c 18)$, Mmp3, Fgr proto-oncogene (Fgr), bone morphogenetic protein 6 (Bmp6), Mmp10, allograft inflammatory factor 1 (Aif), angiotensin I converting enzyme (Ace), early growth response 3 (Egr3), and intercellular adhesion molecule 1 (Icam1). With Notch1 haploinsufficiency, there was further downregulation of histidine ammonia lyase ( Hal), Sox18, plexin A4 opposite strand 1 (Plxna4os1), Oas2 and Gpr31b to less 50\% of the WT BMDMs with IL4/IL13 treatment (Table 3). These data suggest that Notch1 haploinsufficiency may be affecting macrophage polarization through these novel genes (Fig. 2C).

Notch1 haploinsufficiency downregulates unique genes; differential gene expression analysis and RT-qPCR validation. Differentially expressed genes (DEGs) analysis revealed a set of unique genes, which were dysregulated by Notch1 haploinsufficiency at baseline or with different treatments (Table 1). Uninformative genes were removed from initial filtering to minimize the computational graphics and to obtain distinct groups of genes for subsequent analysis. Notch1 haploinsufficiency downregulated the expression of 262 genes under baseline conditions, 307 genes with LPS/IFN- $\gamma$ and 254 genes with IL4/IL13 treatment (Fig. 3A). Notch 1 haploinsufficiency upregulated the expression of 94 genes at baseline conditions, 77 genes with LPS/IFN- $\gamma$ and 66 genes with IL4/IL13 treatment (Fig. 3B). Venn diagram analysis of these DEGs revealed 50 unique genes that were significantly downregulated by Notch1 haploinsufficiency (Fig. 3A,C and Table 1). Functional enrichment analysis and hierarchal clustering predicted that DEGs were associated with a number of pathways involved in macrophage polarization (Casp4, Has1, Cd34, Cdh5, Fmod, Lum, Nbl1, Postn, Plvap), ECM degradation 


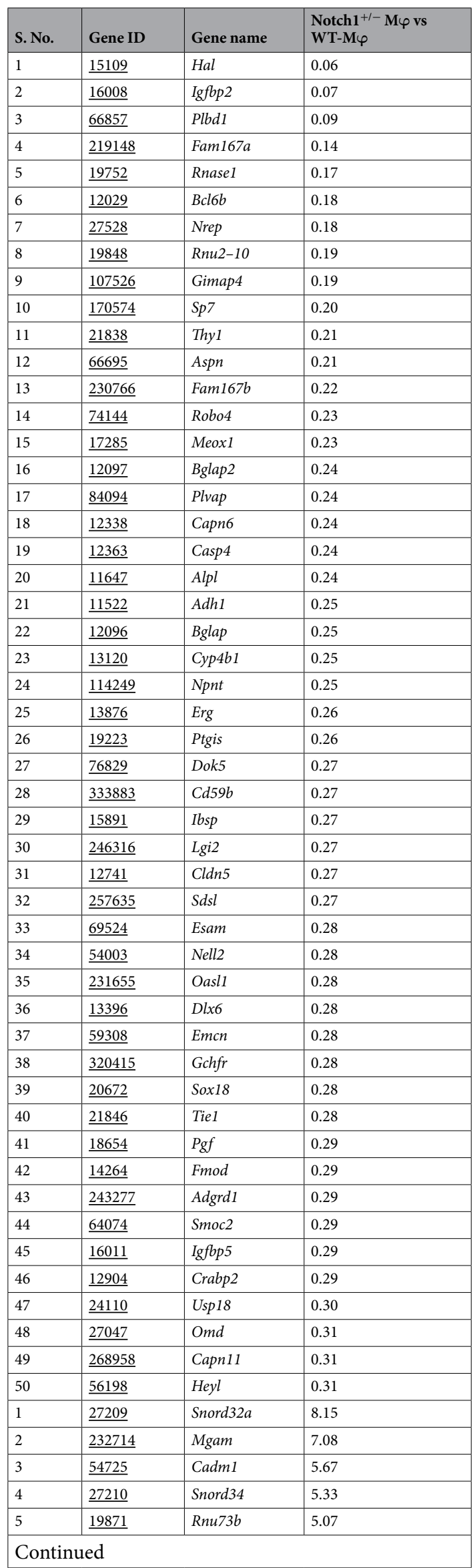




\begin{tabular}{|c|c|c|c|}
\hline S. No. & Gene ID & Gene name & $\begin{array}{l}\text { Notch } 1^{+1-} \text { M } \varphi \text { vs } \\
\text { WT-M } \varphi\end{array}$ \\
\hline 6 & $\underline{18128}$ & Notch1 & 4.90 \\
\hline 7 & $\underline{19225}$ & Ptgs2 & 4.43 \\
\hline 8 & $\underline{387224}$ & Mir29c & 4.15 \\
\hline 9 & $\underline{19874}$ & Rny3 & 4.00 \\
\hline 10 & $\underline{723963}$ & Mir29b-2 & 3.52 \\
\hline 11 & $\underline{436188}$ & Gm5751 & 3.50 \\
\hline 12 & $\underline{71988}$ & Esco 2 & 3.25 \\
\hline 13 & $\underline{208628}$ & Kntcl & 3.20 \\
\hline 14 & $\underline{170947}$ & Myoz3 & 3.19 \\
\hline 15 & $\underline{16323}$ & Inhba & 2.83 \\
\hline 16 & 67121 & Mastl & 2.82 \\
\hline 17 & $\underline{67629}$ & Spc24 & 2.77 \\
\hline 18 & $\underline{64337}$ & Gng13 & 2.70 \\
\hline 19 & $\underline{387216}$ & Mir23a & 2.70 \\
\hline 20 & $\underline{270120}$ & Fat3 & 2.68 \\
\hline 21 & $\underline{11609}$ & Agtr 2 & 2.62 \\
\hline 22 & $\underline{432855}$ & Zfhx2os & 2.62 \\
\hline 23 & $\underline{16551}$ & Kif11 & 2.55 \\
\hline 24 & $\underline{12771}$ & Ccr3 & 2.51 \\
\hline 25 & $\underline{70218}$ & Kif18b & 2.51 \\
\hline 26 & $\underline{387164}$ & Mir146 & 2.45 \\
\hline 27 & $\underline{244218}$ & $C t f 2$ & 2.42 \\
\hline 28 & $\underline{103142}$ & $R d h 9$ & 2.42 \\
\hline 29 & $\underline{208292}$ & Zfp 871 & 2.41 \\
\hline 30 & $\underline{212391}$ & Lcor & 2.33 \\
\hline 31 & $\underline{218581}$ & Depdc1b & 2.31 \\
\hline 32 & $\underline{108912}$ & Cdca2 & 2.31 \\
\hline 33 & $\underline{547347}$ & Gm6034 & 2.30 \\
\hline 34 & $\underline{17345}$ & Mki67 & 2.30 \\
\hline 35 & 97908 & Hist $1 \mathrm{~h} 3 g$ & 2.28 \\
\hline 36 & $\underline{72415}$ & Sgol1 & 2.27 \\
\hline 37 & $\underline{77777}$ & Ulbp1 & 2.26 \\
\hline 38 & $\underline{210530}$ & P3h2 & 2.25 \\
\hline 39 & $\underline{20311}$ & Cxcl5 & 2.24 \\
\hline 40 & $\underline{78316}$ & Platr27 & 2.22 \\
\hline 41 & $\underline{387235}$ & Mir125a & 2.21 \\
\hline 42 & $\underline{449630}$ & Snord15a & 2.21 \\
\hline 43 & $\underline{15258}$ & Hipk2 & 2.21 \\
\hline 44 & $\underline{70466}$ & Ckap2l & 2.20 \\
\hline 45 & $\underline{270160}$ & Rab39 & 2.19 \\
\hline 46 & $\underline{54615}$ & Npff & 2.19 \\
\hline 47 & $\underline{240641}$ & Kif20b & 2.16 \\
\hline 48 & $\underline{654810}$ & Appbp2os & 2.16 \\
\hline 49 & $\underline{218977}$ & Dlgap5 & 2.16 \\
\hline 50 & $\underline{387158}$ & Mir140 & 2.16 \\
\hline
\end{tabular}

Table 2. List of top 50 genes downregulated and upregulated by Notch1 haploinsufficiency. Fold change: up $>2$ fold. Fold change: down $<0.5$ fold.

(Col1a1, col5a3, Fmod, Lum) and osteogenesis (Alpl, Igf2, Igfbp2) (Figs 2C, 3C). The gene expression of Fmod, Casp4, Alpl, Colla1, Igf-bp2 and Lum were validated by real-time qRT-PCR and the data were consistent with the RNA-Seq analyses (Fig. 4A,B and data not shown).

With regard to the expression of Notch1, the qRT-PCR and RNA-Seq data revealed contrasting results. The decreased expression of Notch1 was confirmed in the Notch $1^{+/-}$macrophages by genotyping and qRT-PCR (Supplemental Fig. 3C-F). The downstream target of Notch1 HeyL and its ligand Dll4 were significantly downregulated in both the RNA-Seq and qRT-PCR data confirming that the changes reflected in the RNA-Seq data can be attributed to reduced Notch1 signaling (Supplemental Fig. 1C and Table 2). Moreover, reduction in the downstream targets of Notch1 signaling was also observed in response to DAPT and Notch1 siRNA albeit 
Pathways affected by downregulation of genes with Notchl haploinsufficiency

Pathways affected by upregulation of genes with Notchl haploinsufficiency

A
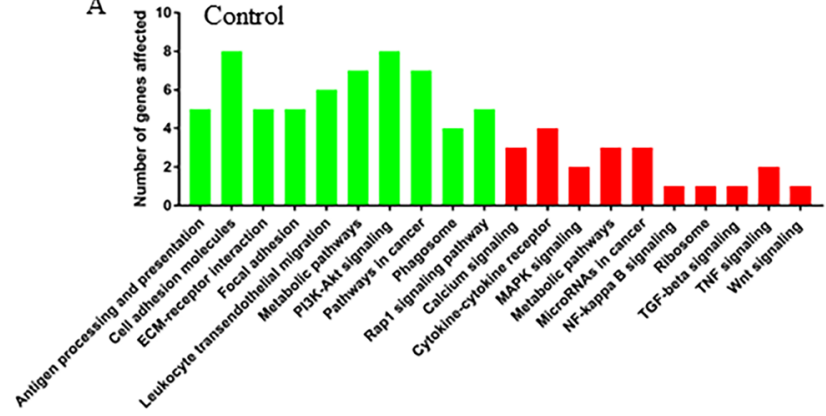

B
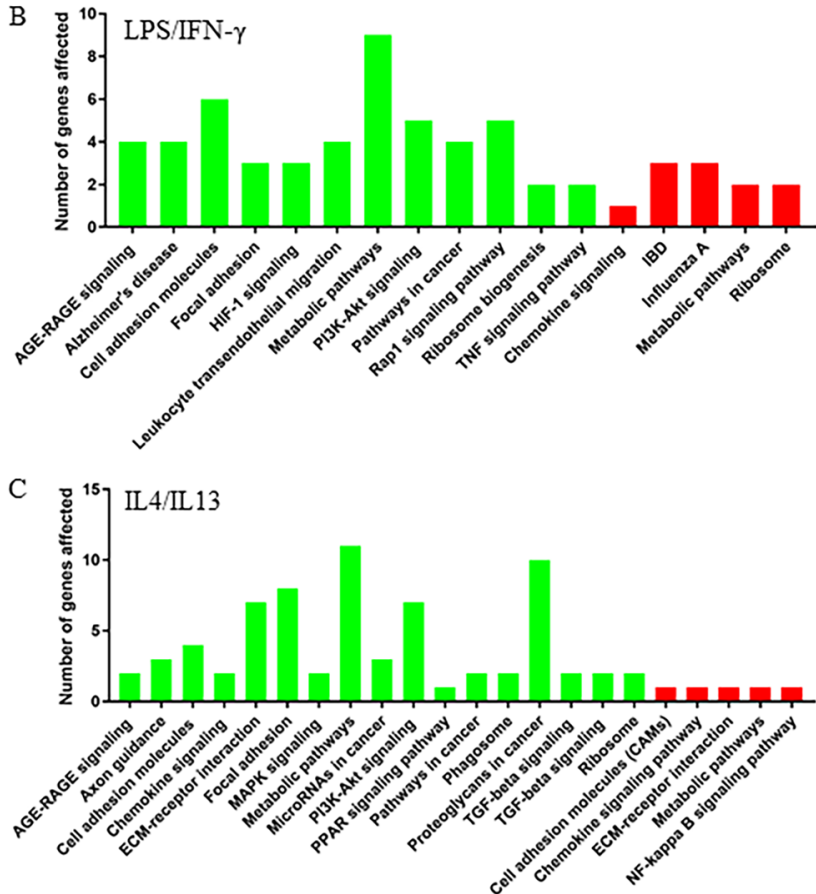

Figure 2. Notch1 haploinsufficiency affects numerous pathways related to macrophage polarization and cytokine/chemokine signaling. Pathway analysis showing the major pathways affected by the downregulation (green) or upregulation (red) of genes by Notch1 haploinsufficiency in naïve macrophages (A), in response to LPS/IFN- $\gamma(\mathbf{B})$ or IL4/IL13 (C). 'Y' axis display the number of genes implicated in each pathway.

at different extent (Supplemental Fig. 3E,F). Overexpression of Notch1 by NICD plasmid on the other hand increased the expression of HeyL, Hes1, Hey1 and Hey2 and Jag1 significantly in the unstimulated macrophages (Supplemental Fig. 3D). These changes were also reflected in the total protein contents of NICD (Supplemental Fig. 3G). Interestingly, RNA-Seq data revealed that the expression of Notch1 was higher in the Notch $1^{+/-}$macrophages than the WT BMDMs. One potential explanation of this discrepancy could be the instability of Notch1 mRNA and susceptibility to degrade in different conditions ${ }^{35-37}$. The evidence for these conflicting observations was demonstrated by the number of reads in WT samples which were strong at the $3^{\prime}$ region (the polyA tail region), but diminished towards the $5^{\prime}$ end of the transcripts (Supplemental Fig. 4A). As the mRNA was enriched by polyA binding during library preparation, only mRNAs with an intact polyA tail would have been included in our sequencing library. Moreover, treatment of macrophages with Actinomycin D and HuR significantly increased expression of Notch1, whereas no significant effect of these stimulants on Dll4 or Fmod was observed (Supplemental Fig. 4B). The analysis of Ensembl Exon numbers for the full-length coding Notch 1 transcript indicate a logical divergence in the results of the Notch1 expression as determined by qRT-PCR or RNA-Seq analysis (Supplemental Fig. 3C-G). Increased read-counts for Notch 1 mRNA expression were only observed in exons 1-19 of the Notch $1^{+/-}$BMDMs, the undeleted portion of Notch 1 allele ${ }^{38}$. Starting with exon $20-33$, very little expression of Notch 1 was observed, which is consistent with the generation of mutated Notch $1^{+/-}$mouse model $^{38}$. Although, these observations are very intriguing, further studies are required to determine the role of Notch1 signaling on RNA integrity using epigenetic and functional approaches. In the following experiments, we focused on the unique genes that were downregulated by Notch1 haploinsufficiency. 


\begin{tabular}{|c|c|c|c|c|}
\hline Gene Name & $\begin{array}{l}\text { WT LPS/IFN- } \gamma \text { vs } \\
\text { WT-M } \varphi\end{array}$ & $\begin{array}{l}\text { Notch } 1^{+-} \text {LPS/IFN- } \gamma \text { vs } \\
\text { Notch } 1^{+-} \text {M } \varphi\end{array}$ & $\begin{array}{l}\text { Notch1 }^{+/-} \text {M } \varphi \text { vs } \\
\text { WT-M } \varphi\end{array}$ & $\begin{array}{l}\text { Notch } 1^{+1-} \text { LPS/IFN- } \gamma \text { vs } \\
\text { WT- LPS/IFN- } \gamma\end{array}$ \\
\hline Snord14c & 5.66 & 0.23 & 2.02 & 0.08 \\
\hline Timd4 & 12.32 & 1.16 & 1.00 & 0.09 \\
\hline Mir214 & 2.43 & 0.31 & 0.82 & 0.11 \\
\hline Rny3 & 2.72 & 0.08 & 4.00 & 0.12 \\
\hline Snord $32 a$ & 6.93 & 0.12 & 8.15 & 0.14 \\
\hline Snhg9 & 2.07 & 0.28 & 1.54 & 0.21 \\
\hline Rnulal & 2.37 & \begin{tabular}{|l|}
0.94 \\
\end{tabular} & 0.56 & 0.22 \\
\hline Gimap9 & 6.68 & 1.46 & 1.02 & 0.22 \\
\hline Bdkrb1 & 6.87 & 2.99 & 0.63 & 0.27 \\
\hline Csf2 & 9.77 & 2.73 & 1.00 & 0.28 \\
\hline Snord $15 a$ & 2.26 & 0.29 & 2.21 & 0.28 \\
\hline Rnu1b2 & 3.54 & 1.00 & 1.00 & 0.28 \\
\hline Bco2 & 2.35 & 1.39 & 0.48 & 0.28 \\
\hline Ankrd1 & 2.79 & 0.83 & 0.97 & 0.29 \\
\hline Rnyl & 5.54 & 1.70 & 0.95 & 0.29 \\
\hline Meikin & 16.35 & 4.80 & 1.00 & 0.29 \\
\hline Lrrc73 & 4.22 & 0.97 & 1.31 & 0.30 \\
\hline Hist1h3a & 2.07 & 0.46 & 1.37 & 0.30 \\
\hline Gabrd & 3.17 & 1.04 & 0.93 & 0.31 \\
\hline Slc25a18 & 5.69 & 1.51 & 1.16 & 0.31 \\
\hline Ly6g & 3.17 & 1.00 & 1.00 & 0.32 \\
\hline Illrl1 & 7.75 & 2.67 & 0.95 & 0.33 \\
\hline Scin & 4.87 & 1.60 & 1.00 & 0.33 \\
\hline$I l 2 r b$ & 3.00 & 1.28 & 0.80 & 0.34 \\
\hline Crnde & 2.23 & 1.03 & 0.74 & 0.34 \\
\hline Hba-a2 & 4.55 & 1.39 & 1.14 & 0.35 \\
\hline Gzmc & 2.22 & 0.40 & 1.94 & 0.35 \\
\hline Slc36a2 & 7.64 & 3.02 & 0.89 & 0.35 \\
\hline Has1 & 29.65 & 22.78 & 0.46 & 0.35 \\
\hline Mir101a & 2.60 & 2.05 & 0.46 & 0.36 \\
\hline Tyro3 & 2.12 & 1.23 & 0.63 & 0.37 \\
\hline Calb2 & 201.21 & 74.30 & 1.00 & 0.37 \\
\hline Hba-al & 3.80 & 1.41 & 1.00 & 0.37 \\
\hline$L b p$ & 13.65 & 4.41 & 1.16 & 0.37 \\
\hline Gimap4 & 5.63 & 11.21 & 0.19 & 0.38 \\
\hline Madcam 1 & 20.43 & 8.79 & 0.88 & \begin{tabular}{|l|}
0.38 \\
\end{tabular} \\
\hline Casp4 & 15.46 & 24.54 & 0.24 & 0.38 \\
\hline Tmem132e & 26.36 & 10.15 & 1.00 & \begin{tabular}{|l|}
0.38 \\
\end{tabular} \\
\hline Dact2 & 4.84 & 2.60 & 0.72 & 0.39 \\
\hline Cdhr1 & 2.26 & 0.92 & 0.95 & 0.39 \\
\hline Fam84a & 4.90 & 1.92 & 1.00 & 0.39 \\
\hline Hs3st1 & 3.86 & 2.27 & 0.68 & 0.40 \\
\hline Spink2 & 14.66 & 5.90 & 1.00 & 0.40 \\
\hline Tnfrsf 18 & 2.74 & 1.48 & 0.74 & 0.40 \\
\hline Mmp8 & 0.10 & 0.18 & 1.94 & 3.25 \\
\hline Mmp12 & 0.12 & 0.18 & 1.55 & 2.21 \\
\hline Tlr8 & 0.06 & \begin{tabular}{|l|}
0.08 \\
\end{tabular} & 1.64 & 2.18 \\
\hline Lipn & 0.17 & 0.18 & 2.03 & 2.15 \\
\hline Mrcl & 0.06 & 0.08 & 1.55 & 2.06 \\
\hline Dhrs 9 & 0.30 & 0.37 & 1.63 & 2.04 \\
\hline Gene Name & $\begin{array}{l}\text { WT IL4/IL13 vs } \\
\text { WT-M } \varphi\end{array}$ & $\begin{array}{l}\text { Notch1 }^{+/-} \text {IL4/IL13 vs } \\
\text { Notch1 }^{+-} \text {M } \varphi\end{array}$ & $\begin{array}{l}\text { Notch1 } 1^{+/-} \text {M } \varphi \text { vs } \\
\text { WT-M } \varphi\end{array}$ & $\begin{array}{l}\text { Notch1 } 1^{+/-} \text {IL4/IL13 vs } \\
\text { WT IL4/IL13 }\end{array}$ \\
\hline Prl2c3 & 2.31 & 9.00 & 1.13 & 4.40 \\
\hline Prl2c2 & 3.16 & \begin{tabular}{|l|}
14.48 \\
\end{tabular} & 0.93 & 4.26 \\
\hline Snord $32 a$ & 3.01 & 1.09 & 8.15 & 2.94 \\
\hline Snora $74 a$ & 2.44 & 4.71 & 1.40 & 2.70 \\
\hline
\end{tabular}




\begin{tabular}{|c|c|c|c|c|}
\hline Gene Name & $\begin{array}{l}\text { WT LPS/IFN- } \gamma \text { vs } \\
\text { WT-M } \varphi\end{array}$ & $\begin{array}{l}\text { Notch } 1^{+-} \text {LPS/IFN- } \gamma \text { vs } \\
\text { Notch } 1^{+-} \text {M } \varphi\end{array}$ & $\begin{array}{l}\text { Notch1 }^{+/-} \text {M } \varphi \text { vs } \\
\text { WT-M } \varphi\end{array}$ & $\begin{array}{l}\text { Notch } 1^{+1-} \text { LPS/IFN- } \gamma \text { vs } \\
\text { WT- LPS/IFN- } \gamma\end{array}$ \\
\hline Oc-stamp & 4.14 & 10.82 & 1.00 & 2.61 \\
\hline Hist1h3g & 2.34 & 2.13 & 2.28 & 2.07 \\
\hline Car3 & 2.27 & 4.93 & 0.94 & 2.04 \\
\hline $\mathrm{Hal}$ & 0.36 & 0.59 & 0.06 & 0.10 \\
\hline Sox18 & 0.49 & 0.45 & 0.28 & 0.26 \\
\hline Dio3 & 0.28 & 0.08 & 1.02 & 0.28 \\
\hline Slc24a3 & 0.32 & 0.12 & 0.84 & 0.32 \\
\hline Itgbll & 0.34 & 0.16 & 0.76 & 0.37 \\
\hline Rnase1 & 0.49 & 1.12 & 0.17 & 0.38 \\
\hline Bclob & 0.41 & 0.90 & 0.18 & 0.39 \\
\hline Kcnmb4os 1 & 0.42 & 0.43 & 0.39 & 0.39 \\
\hline$T g f b i$ & 0.43 & 0.15 & 1.25 & 0.43 \\
\hline Robo4 & 0.44 & 0.83 & 0.23 & 0.43 \\
\hline Cyp4b1 & 0.31 & 0.56 & 0.25 & 0.45 \\
\hline $\mathrm{Nid} 2$ & 0.37 & 0.21 & 0.77 & 0.45 \\
\hline Thsd7a & 0.46 & 0.27 & 0.78 & 0.46 \\
\hline Plxna4os1 & 0.37 & 0.28 & 0.61 & 0.46 \\
\hline Oas2 & 0.49 & 0.46 & 0.49 & 0.47 \\
\hline$S d s l$ & 0.39 & 0.66 & 0.27 & 0.47 \\
\hline Egfl7 & 0.43 & 0.53 & 0.37 & 0.47 \\
\hline Emcn & 0.44 & 0.74 & 0.28 & 0.47 \\
\hline Cldn1 & 0.43 & 0.21 & 0.96 & \begin{tabular}{|l|}
0.48 \\
\end{tabular} \\
\hline Rasip1 & 0.46 & 0.57 & 0.39 & 0.48 \\
\hline Spata33 & 0.40 & 0.14 & 1.33 & 0.48 \\
\hline Gpr31b & 0.41 & 0.37 & 0.52 & 0.48 \\
\hline Tmem121 & 0.43 & 0.33 & 0.66 & 0.50 \\
\hline
\end{tabular}

Table 3. List of top genes dysregulated by Notch1 haploinsufficiency in the presence of LPS/IFN- $\gamma$ and IL4.

Gain and loss-of-function studies suggest that Notch1 directly regulates Fmod and Casp4. Among the 50 genes downregulated by Notch 1 haploinsufficiency, Fmod and Casp 4 were further evaluated because of their potential involvement in macrophage polarization ${ }^{39-41}$. In agreement with the RNA-Seq results, downregulation of expression for Fmod (Fig. 4A) and Casp4 (Fig. 4B) was confirmed in the BMDMs from Notch $^{+/-}$mice by real-time qRT-PCR. DAPT, a potent inhibitor of Notch signaling also reduced the gene expression of Fmod to less than 50\% of the baseline levels (Fig. 4A). However, expression of Casp 4 was not significantly altered with DAPT treatment (Fig. 4B). Decreased expression Fmod and Casp4 genes was also observed in $A p o e^{-1-}$ BMDMs by Notch1 haploinsufficiency suggesting that these effects were global and independent of the strain (Fig. 4C,D). Next, we performed gain and loss-of-function studies using NICD plasmids or specific Notch1 siRNA respectively (Fig. 4E,F). Overexpression of Notch1 by NICD plasmid increased the expression of Fmod by almost 1.5 fold, whereas Notch1 siRNA reduced the expression of Fmod below 50\% (Fig. 4E,F). Co-immunostaining with Fmod and Tgf- $\beta 2$ demonstrated strong immunoreactivity for Fmod in WT BMDMs with a concomitant weak immunoreactivity for Tgf- 32 (Fig. 4G-N). On the contrary, in Notch $1^{+1-}$ BMDMs, weak immunoreactivity for Fmod and strong immunoreactivity for Tgf- $\beta 2$ was observed (Fig. 4K,N). The quantitation of double immunofluorescence (DIF) showed inverse correlation between Tgf- 32 and Fmod immunoreactivity in WT and Notch1 ${ }^{+-}$BMDMs (Fig. 4O). Collectively, our data clearly suggest that Notch1 is involved in the modulation of Fmod expression.

Further, we confirmed that Notch1 haploinsufficiency markedly decreased the Fmod protein content significantly, both at baseline levels and in response to LPS/IFN- $\gamma$ treatment (Fig. 5A,B). Overexpression of NICD in these BMDMs significantly increased the Fmod protein contents (Fig. 5C,D). Treatment of macrophages with human recombinant FMOD ( $400 \mathrm{ng} / \mathrm{ml} ; 24 \mathrm{~h}$ ) significantly decreased the expression of common M2 genes including Tgf- $\beta 1, T g f-\beta 2, A r g 1, C d 206$ and Il4 (Fig. 5F). Interestingly, no significant effect of FMOD on M1 genes was observed in these settings (Fig. 5E), suggesting that these effects of FMOD on M2-polarization may be mediated by Tgf- $\beta 2$. To confirm direct interactions between FMOD and Tgf- $\beta 2$, we performed immunoprecipitation studies using Dynabeads ${ }^{\circledR}$ Co-Immunoprecipitation Kit (ThermoFisher). Western blotting of the immunoprecipitate with FMOD revealed the presence of Tgf- $\beta 2$ in the Notch ${ }^{+/-}$macrophages, whereas in the WT macrophages, the contents of Tgf- $\beta 2$ were minimal (Fig. 5G). These data confirm that FMOD protein is physically associated with Tgf- $\beta 2$ and also provide evidence for increased contents of Tgf- $\beta 2$ in Notch 1 haploinsufficient macrophages.

As demonstrated by qRT-PCR (Fig. 4A-D) and Western blot (Fig. 5A-D and Supplemental Fig. 5A), the expression of Fmod was not significantly affected by LPS/IFN- $\gamma$ treatment. LPS/IFN- $\gamma$ treatment reduces Tgf- $\beta$ signaling as demonstrated by various studies, but the mechanism is unknown ${ }^{20,21,42,43}$. We determined if these effects of LPS/IFN- $\gamma$ on Tgf $-\beta$ are mediated by Fmod. Macrophages were exposed to differing concentrations of LPS $(0,5,10,25,50$ or $100 \mathrm{ng} / \mathrm{ml})$ and $20 \mathrm{ng} / \mathrm{ml}$ of IFN- $\gamma$ for $24 \mathrm{~h}$, thereafter protein extracts were examined 


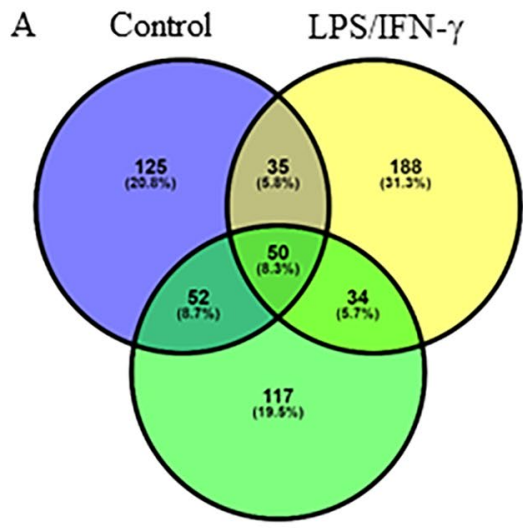

IL $4 /$ IL 13

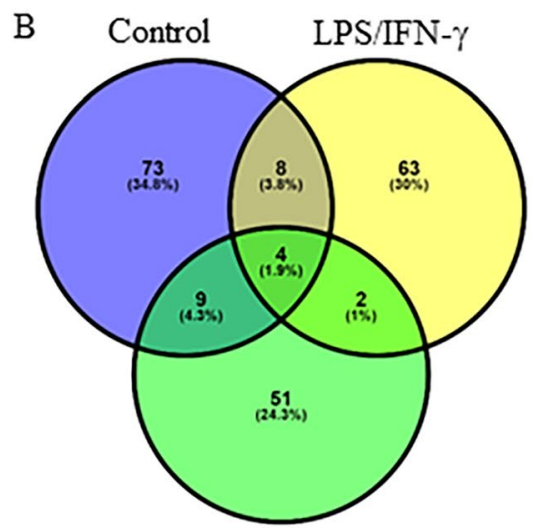

IL $4 /$ IL 13

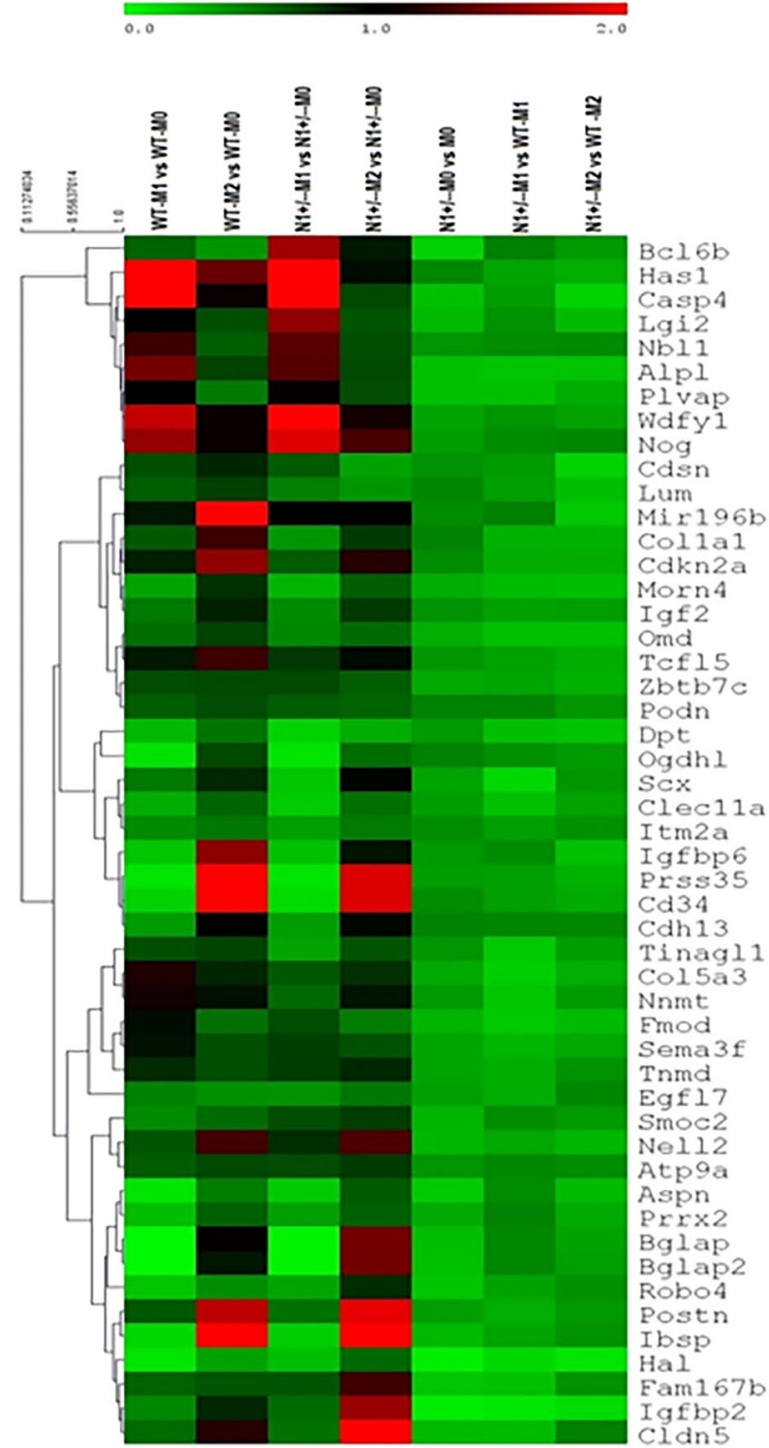

Figure 3. Differentially expressed genes (DEGs) analysis revealed a set of unique genes dysregulated by Notch1 haploinsufficiency. (A) Venn diagram showing the number of genes downregulated (less than 0.5-fold) in Notch $1^{+/-}$BMDMs treated with vehicle, LPS-IFN- $\gamma$ or IL4/IL13 to WT BMDMs with similar regimen. (B) Venn diagram showing the number of genes upregulated (more than 2-fold) in Notch ${ }^{+1-}$ BMDMs treated with vehicle, LPS/IFN- $\gamma$ or IL4/IL13 to WT with similar regimen. Each portion of a Venn diagram displays number of DEGs in Notch $1^{+l-}$ BMDMs compared to WT BMDMs. (C) Heat map from 50 common mouse genes downregulated in Notch1 ${ }^{+/-}$BMDMs with all the treatments than WT BMDMs with similar regimen.

by Western blotting. LPS treatment did not change total Fmod protein content $(60 \mathrm{kd})$, but a dose-dependent decrease in the cleaved Fmod fragment was observed (33kd; Fig. 6A-F and Supplemental Fig. 5B). A concomitant decrease in the Tgf- $\beta 2$ protein content was also observed with LPS/IFN- $\gamma$ treatment (Fig. 6A,F). Proteolysis of Fmod through Mmp8 has been shown to increase the expression of Tgf- $\beta 2^{39}$. We also observed a dose-dependent decrease in the Mmp8 content, which correlated directly with Tgf- 32 expression and inversely with NICD expression (Fig. 6A,C).

Finally, we determined if Notch1 signaling affects the expression of downstream targets of the Tgf- $\beta$ signaling pathway and if this was mediated by Fmod. BMDMs from WT or Notch $1^{+/-}$were treated with either FMOD $(400 \mathrm{ng} / \mathrm{ml})$ or activated MMP8 $(400 \mathrm{ng} / \mathrm{ml})$ for $24 \mathrm{~h}$. Treatment with FMOD significantly decreased the expression of Tgf- $\beta 2(0.18 \pm 0.03$; Fig. $7 \mathrm{~B})$, Tgf- $\beta \mathrm{RI}(0.45 \pm 0.02$; Fig. $7 \mathrm{C})$ and Smad3 $(0.23 \pm 0.04$; Fig. $7 \mathrm{~F})$, whereas treatment with activated-MMP8 significantly increased the expression of Tgf- $\beta 2(1.42 \pm 0.11$; Fig. 7B) in macrophages. With DAPT pretreatment, there was lesser but insignificant decrease in expression of Tgf- $\beta 2$ with FMOD treatment ( 0.35 fold; Fig. $7 \mathrm{~B})$. In response to MMP8, increased trend was observed in the Tgf- $\beta 2$ expression but did not reach significance (1.66 \pm 0.13 ; Fig. $7 \mathrm{~B})$. No change in the expression of Tgf- $\beta 1$ or Smad3 was observed in DMSO-treated macrophages, whereas in DAPT-treated macrophages, the expression of Tgf- $\beta 1$ (1.73 \pm 0.06 ; Fig. $7 \mathrm{~A})$ and $\operatorname{Smad} 3$ (2.05 \pm 0.70 ; Fig. $7 \mathrm{~F})$ increased significantly in response to MMP8. 

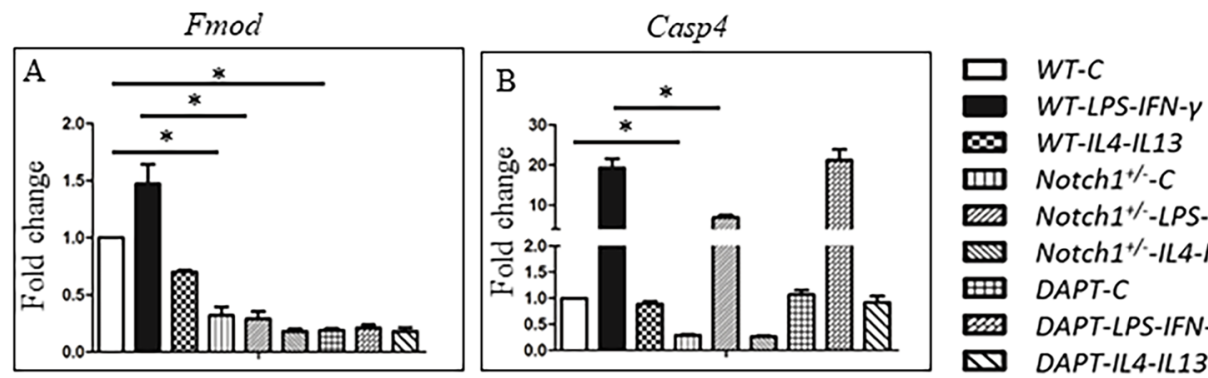

$\infty$ WT-IL4-IL13

血 Notch $1 \%-C$

ImS Notch $1 \%$-LPS-IFN- $Y$

Notch $1^{+/}-$IL4-IL13

曲 DAPT-C

DAPT-LPS-IFN- $\gamma$
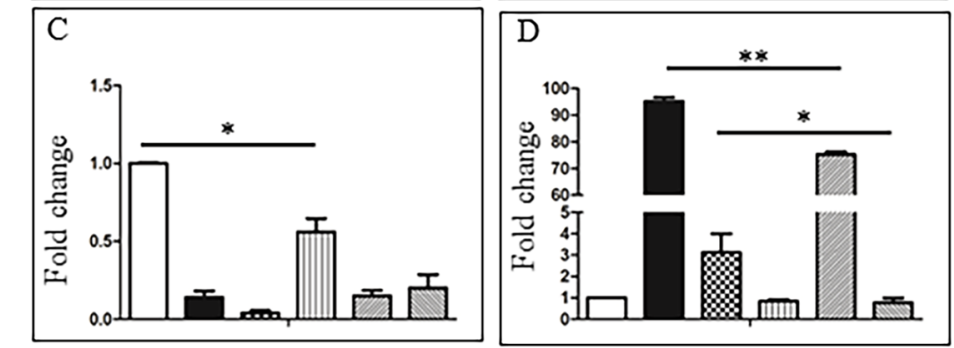

DAPT-IL4-IL13
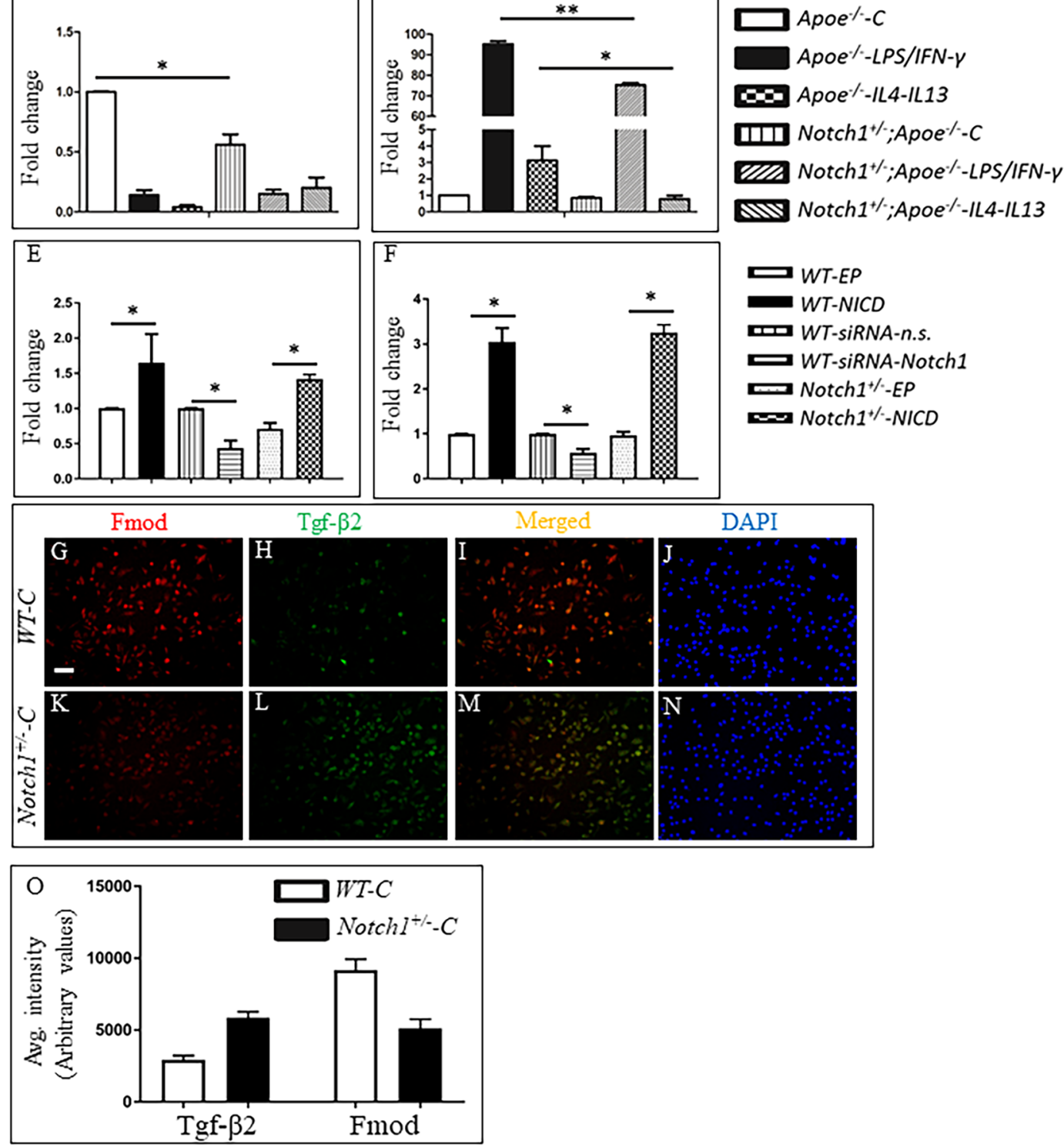

Figure 4. Quantitative real-time PCR validates the RNA-Seq data for fibromodulin (Fmod) and Caspase-4 (Casp4). (A,B) Bar graphs represent fold change in gene expression of Fmod and Casp4 in WT, Notch1 ${ }^{+/-}$BMDMs and WT + DAPT (a potent inhibitor of Notch signaling). BMDMs were pre-treated with DMSO or DAPT for 24h followed by LPS/IFN- $\gamma$ or IL4/IL13 for $24 \mathrm{~h}$. (C,D) Bar graphs represent the gene expression of Fmod and Casp4 in $A$ poe $e^{-/-}$, Notch $^{+/-} ; A$ poe $e^{-/-}$BMDMs treated with LPS/IFN- $\gamma$ or IL4/IL13 for $24 \mathrm{~h}$. (E,F) Graphs represent fold change in the expression of Fmod and Casp4 in WT, or Notch $1^{+/-}$BMDMs $48 \mathrm{~h}$ post transfection with Notch1 intracellular domain (NICD) plasmid or siRNA-Notch1. Gene expression was determined using qPCR, normalized to Rpl13a and reported as fold change (mean $\pm \mathrm{SEM}, \mathrm{n}=3$ for each group) to WT-C or Apoe ${ }^{-l-} \mathrm{C}$. (G-N) Double immunofluorescence (DIF) staining of BMDMs revealing the pattern of expression of Fmod $(\mathbf{G}, \mathbf{K})$, Tgf- $\beta 2(\mathbf{H}, \mathbf{L})$ and their merged images $(\mathbf{I}, \mathbf{M})$. Nuclei are shown in blue DAPI staining (J, N). (O) Quantification of DIF staining of BMDMs using Lionheart FX Gene 5 software. The data is represented as average intensity of $\sim 200$ cells from each group. Original magnification $40 \times$, Scale bars $=50 \mu \mathrm{m} . * * * p<0.001, * * p<0.01, * p<0.05$ (one way ANOVA followed by a Tukey's multiple comparisons test comparisons test). (EP=empty plasmid). 

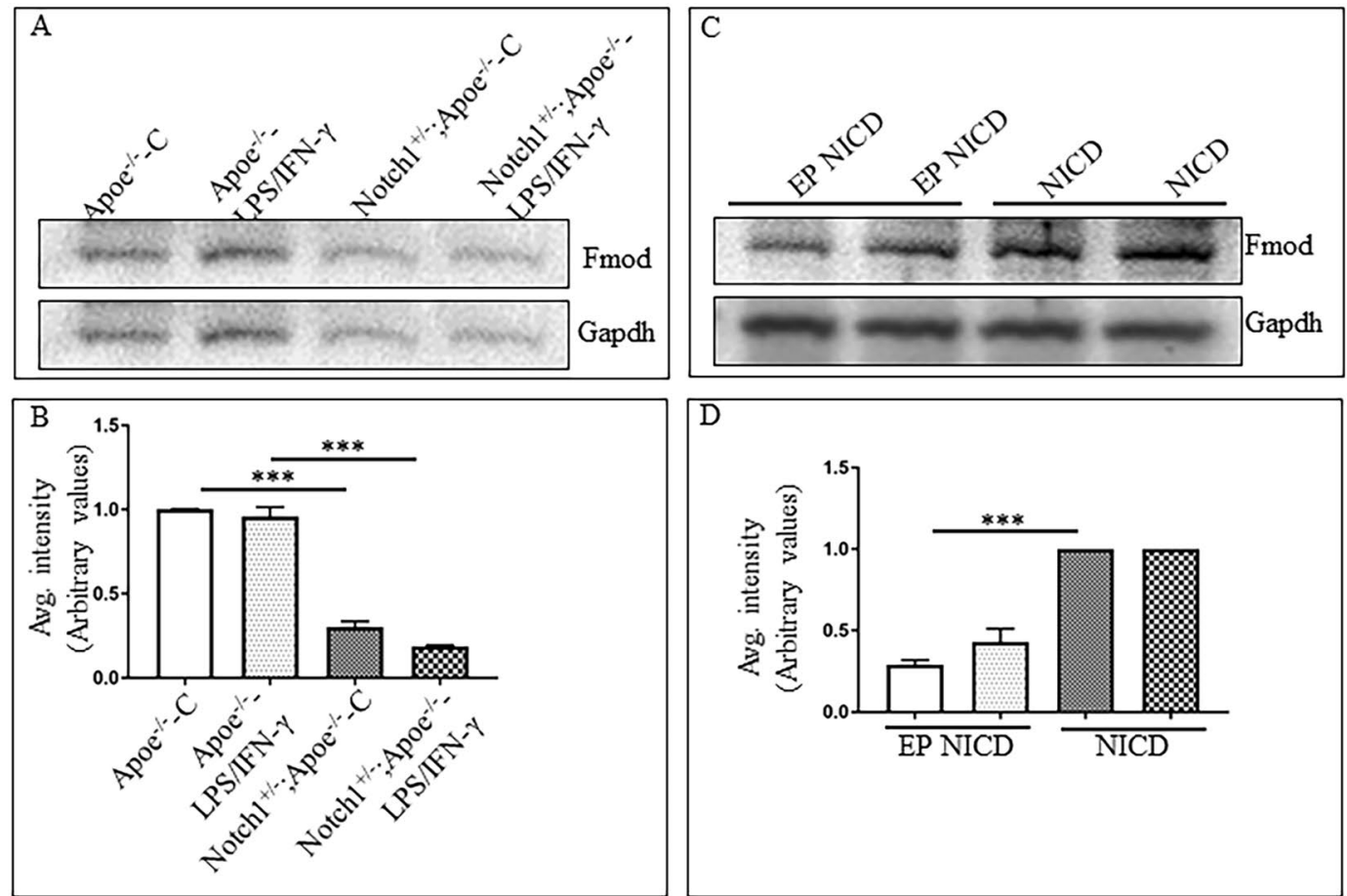

$\mathrm{D}$
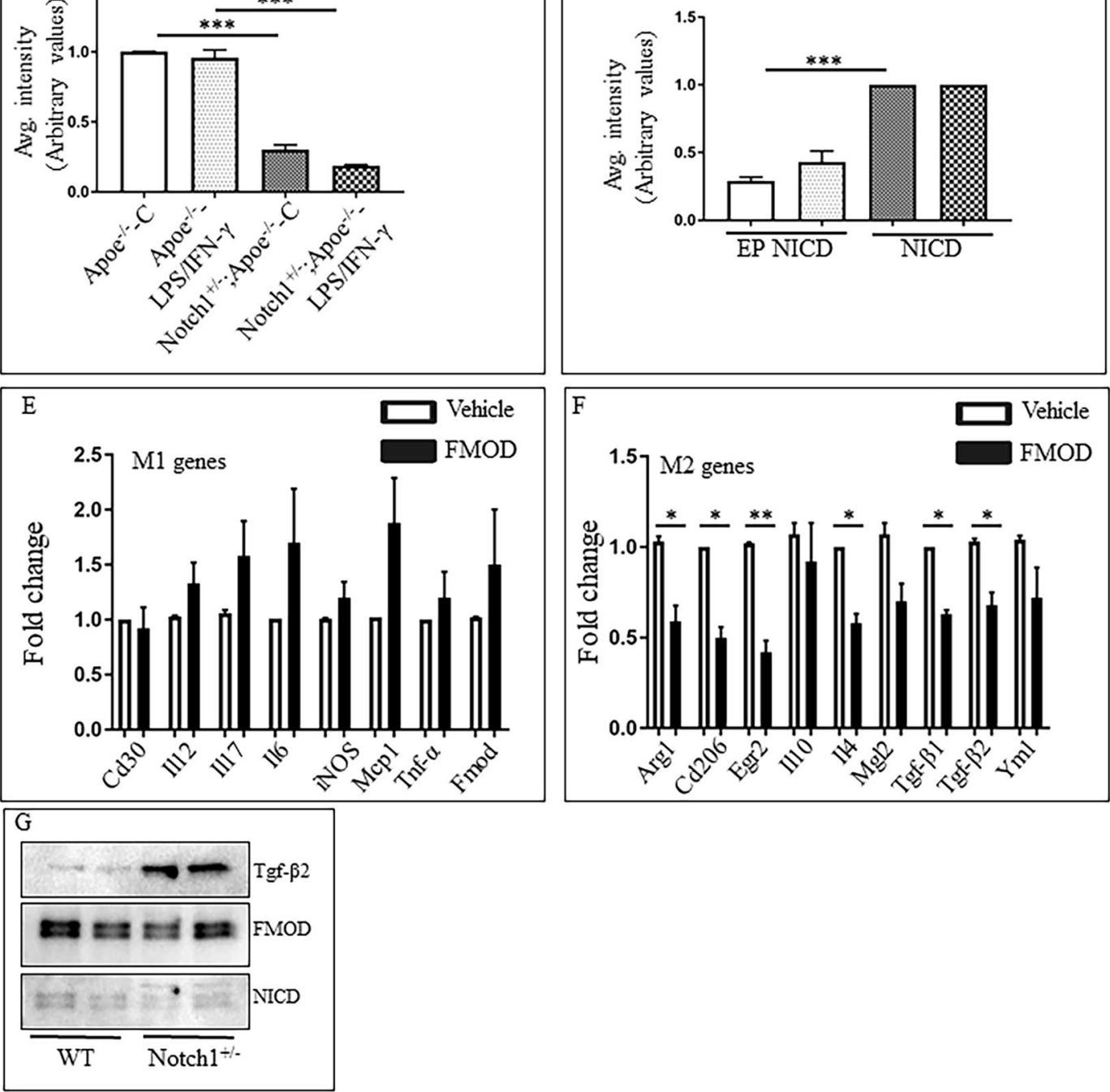

Figure 5. Overexpression of NICD increases the total Fmod protein contents in BMDMs and LPS prevents the cleavage of Fmod in a dose dependent manner. $(\mathbf{A}, \mathbf{B})$ WB shows the expression of total Fmod in Apoe $e^{-1-}$ and Notch1 ${ }^{+/-} ;$Apoe $^{-/-}$BMDMs and quantification of three replicates as determined by Image J. (C,D) WB showing the total Fmod protein content in WT BMDMs $48 \mathrm{~h}$ post transfection with empty or NICD plasmids and the quantification of the immunoblots. (E,F) qRT-PCR showing the panel of M1 and M2 genes dysregulated with human recombinant FMOD $(400 \mathrm{ng} / \mathrm{ml}$ for $24 \mathrm{~h})$. (G) Co-immunoprecipitation showing contents of Tgf- $\beta 2$, Fmod and NICD proteins pulled down with Fmod antibody from the $W T$ and $N o t c h 1^{+/-}$peritoneal macrophages.

No significant changes in the expression of Tgf-ßRI (Fig. 7C) or Smad2 (Fig. 7E) expression were observed in response to FMOD or MMP8 in DMSO or DAPT-treated macrophages suggesting that these contrasting effects of FMOD and MMP8 are selective and specific. We also determined the release of secreted Tgf- $\beta 2$ in the media in response to various stimuli. FMOD did not affect the secreted Tgf- $\beta 2$ protein in the media in Apoe $e^{-/-}$ BMDMs (Fig. 7G,H) whereas with Notch1 haploinsufficiency, the secreted Tgf- $\beta 2$ contents remained higher in the unstimulated as well as in the presence of FMOD (Fig. 7G,H). 

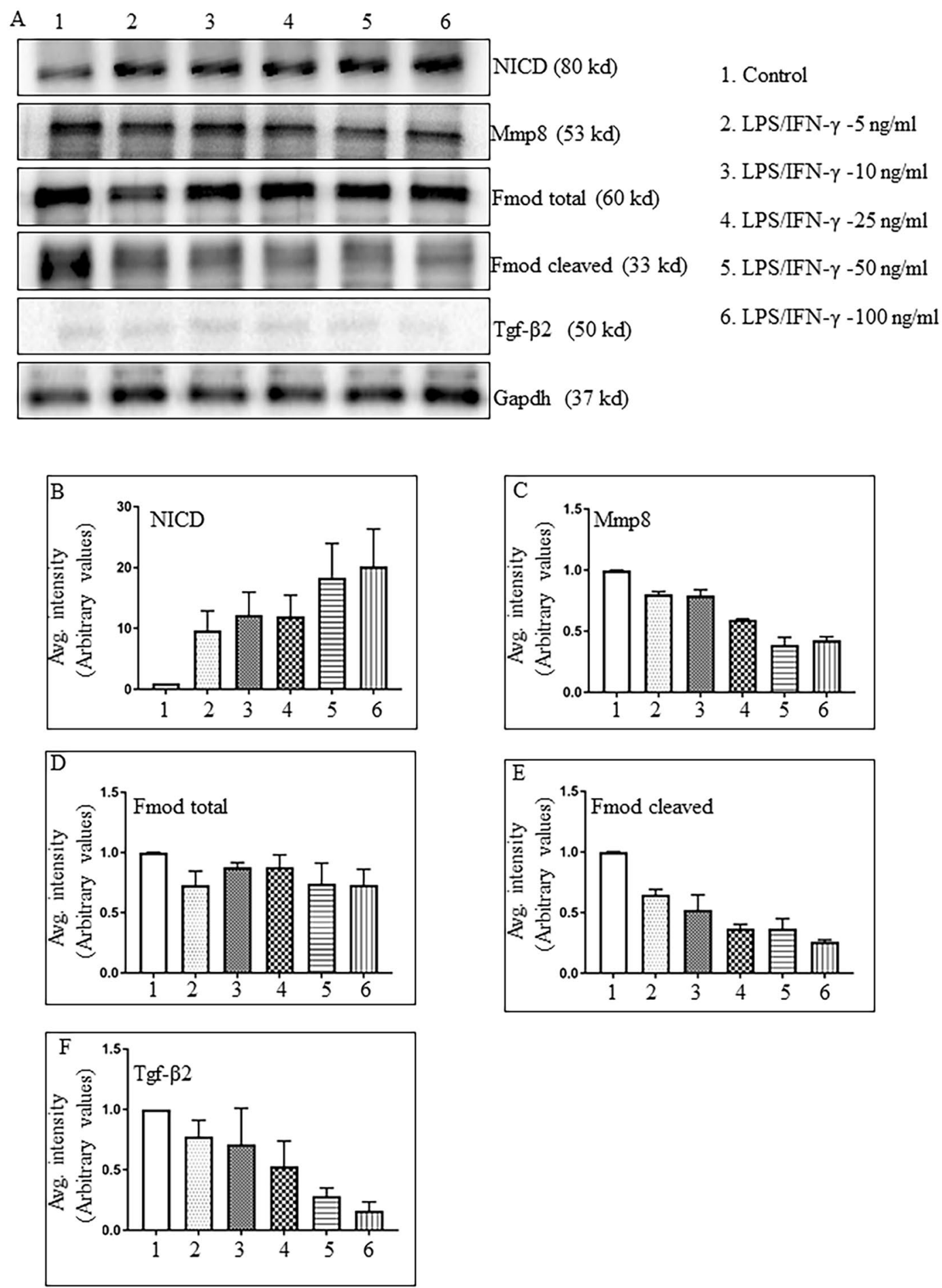

Figure 6. Dose-dependent effects of LPS/IFN- $\gamma$ on Tgf- $\beta$ expression are associated with changes in the cleaved Fmod fragments. (A) Representative WB image showing the contents of NICD, Mmp8, total Fmod, cleaved Fmod, Tgf- $\beta 2$ and Gapdh in macrophages in response to increasing dose of LPS $(0,5,10,25,50 \mathrm{or} 100 \mathrm{ng} / \mathrm{ml})$ for $24 \mathrm{~h}$. (B-F) Quantitation of immunoblots for NICD, Mmp8, total Fmod, cleaved Fmod, Tgf- $\beta 2$ respectively (average of three replicates shown after normalizing the intensity with Gapdh. (WB = Western blot).

\section{Discussion}

The concept of M1 and M2 polarization (classical and alternative, respectively), although very complex, is increasingly becoming relevant to the pathogenesis of a number of vascular and inflammatory diseases. The key factors that modulate polarization are not well understood, limiting the utilization of this concept as a therapeutic target. We have previously shown that haploinsufficiency of Notch1 favors the transition of naïve $(\mathrm{M} \varphi) \mathrm{mac}-$ rophages to the anti-inflammatory M2-phenotype; however the mechanism is still obscure ${ }^{19-21}$. Using RNA-Seq 
and subsequent validation, we have identified 50 differentially expressed genes (DEGs) in Notch $1^{+/-}$macrophages under different treatments. Mapping these DEGs using the GO database ${ }^{33}$ and with KEGG pathways enrichment analysis ${ }^{34}$, we demonstrated that many of these novel genes are involved in biological pathways necessary during the initiation of inflammation, ECM pathway and macrophage polarization. Of particular note, gain and loss-of-function studies confirmed that Notch1 signaling regulates the expression of Fmod, a proteoglycan family protein, which is involved in Tgf- $\beta$ mediated M2 polarization of macrophages. Fmod is a $42-80 \mathrm{kd}$ cytosolic protein, belonging to the class 2 small leucine-rich proteoglycan family (SLRPs) and is involved in regulation of collagen fibrillogenesis, cell adhesion, modulation of cytokine activity, and prevention of apoptosis ${ }^{44}$. Recent reports suggest that Fmod binds to Tgf- $\beta$ ligands, and a decrease in the total protein of Fmod, or increased degradation of Fmod by Mmp8 may cause increased activity of Tgf- $\beta 2^{39,40,45}$. However, the implications of such binding in macrophage polarization have not been elucidated. Because of close associations of Fmod with Tgf- $\beta$ signaling pathways, we speculate that Notch1 haploinsufficiency may be promoting M2 macrophages by regulating Fmod gene expression and/or its activity. In our studies, Fmod not only decreased the expression of Tgf- $\beta 2$, but also decreased the expression of various genes associated with M2-polarization. Interestingly, no change in the expression of M1-related genes was observed in macrophages with the addition of Fmod suggesting that Fmod have specific roles in M2-poalrization of macrophages (Fig. 8). Further studies are required to confirm the direct crosstalk between Notch1 signaling and Fmod in the context of a disease model.

Notch1 haploinsufficiency dysregulated numerous genes at baseline conditions or in response to stimulants. While the associations of some of these genes with Notch1 signaling have been described in the literature, our study revealed novel genes that may potentially play active roles in the M1 or M2 polarization of macrophages. Among the several genes downregulated by Notch1 haploinsufficiency at baseline conditions, Nog, Alpl and Collal genes, seem to be the most prominent. These genes have been associated with osteogenic pathways, but their association with macrophage polarization is still emerging ${ }^{46-48}$. Among the other genes downregulated by Notch1 haploinsufficiency, Has1 is critical for the synthesis of hyaluronan, a constituent of the vascular ECM and an important ligand for monocyte recruitment and retention ${ }^{49}$. Gimap4 belongs to GTPase of the immunity-associated protein family proteins which are most extensively expressed in the course of Th1 differentiation, and less so during Th2 differentiation. Among the genes upregulated by Notch1 haploinsufficiency at baseline conditions, Mgam has recently been suggested to mediate alternative activation of macrophages in integrin- 36 -deficient mice ${ }^{50}$. In addition, Gng13 belongs to a class of G protein-coupled receptors family and implicated in the activation of Tgf $-\beta^{51}$. Thus, these findings are highly suggestive of the involvement of Notch1 signaling in macrophage functions through these novel genes.

Notch 1 haploinsufficiency reduced the expression of $\sim 100$ genes, which were upregulated with LPS/IFN- $\gamma$ treatment in WT mice. While the literature has demonstrated relationships among Timd4, Csf2, Ly6g, Il1r1, Madcam, Casp4 and Ccl19 and macrophage polarization ${ }^{52,53}$, there is limited data regarding the association of these genes with Notch1 signaling. In addition, RNA-Seq data revealed new targets for Notch1 haploinsufficiency on M1-polarization including Has1, or Spink2, Cngb3 and Kcna4. The upregulation of several genes including Mrc1, Dhrs9, Mmp8, and Lipn by Notch1 haploinsufficiency in the presence of LPS/IFN- $\gamma$ suggest that Notch1 signaling may have wider applications in the polarization of macrophages. Mrc1 is a well-established modulator of alternatively activated M2 macrophages ${ }^{54}$. DHRS9 has very recently been identified as a specific and stable marker of human regulatory macrophage $(\mathrm{Mregs})^{55}$. Mmp8, a relatively less studied member of the MMP family, has received increasing attention in recent years because of its involvement in M2-polarization by modulation Tgf- $\beta$ bioavailability ${ }^{39}$. Macrophages derived Mmp8-deficient mice expressed higher levels of M1-polarization markers but lower levels of M2-polarization markers ${ }^{39}$. Taken together, these findings strengthen the causative roles of Notch1 haploinsufficiency in the regulation of M2 polarization by multiple mechanisms.

The upregulation of certain genes including Prl2c2, Prlc2c3, Snord32a, Snora74a, Oc-stamp and Car3 by Notch1 haploinsufficiency in response to IL4/IL13 is particularly intriguing. Prl2c2 and Prl3c3 belong to the prolactin/somatotropin/placental lactogen family of peptide hormones. In a recent study, expression profiling of macrophages revealed upregulation of $\operatorname{Pr} 2 \mathrm{c} 2$ and $\operatorname{Prl} 3 \mathrm{c} 3$ and their association with M2-polariztion ${ }^{56}$. Recent studies have shown that small nucleolar RNAs (Snord and Snora) function as regulators of metabolic stress response pathways in mammalian cells and also have been implicated in cancer development and progression ${ }^{57}$. Oc-stamp is a RANKL-induced, multi-pass transmembrane protein that promotes the formation of multinucleated osteoclasts and is strongly upregulated in primary pre-osteoclasts ${ }^{45}$. Oc-stamp requires STAT6 and IL4 signaling for its activation ${ }^{58}$. Carbonic anhydrases are osteoclastogenic genes and have been associated with mannose receptor-positive M2 macrophages ${ }^{59}$. It will be interesting to determine if Notch1 haploinsufficiency promotes M2 polarization of macrophages through these genes.

With Notch1 haploinsufficiency, there was a downregulation of few genes to less than $50 \%$ of the WT BMDMs in the presence of IL4/IL13 including histidine ammonia lyase (Hal), Sox18, plexin A4 opposite strand 1 (Plxna4os1), Oas2 and Gpr31b. Hal initiates the catabolism of anti-inflammatory histidine into histamine thus making the cells susceptible to pro-inflammatory factors and pro-oxidant ${ }^{60}$. Sox 18 is a transcription factor critically required for tumor-induced lymphangiogenesis, and suppressing Sox 18 function impedes tumor metasta$\operatorname{sis}^{61}$. The instability of Notch 1 and its susceptibility to degradation has been well reported in the literature ${ }^{37,62-64}$. In our RNA-Seq analysis, genes related to RNA degradation (Cnot1, Cnot6, Cnot61, Lsm6, and Ttc37), RNA polymerase (Polr2a, Polr2f, Polr3b and Znrd1) and RNA transport (Cyfip2, Eif2b2, Kpnb1, Ndc1, Nxt1and Ranbp2) were dysregulated by Notch1 haploinsufficiency suggesting its role in RNA degradation. Oas2 belong to members of RNA polymerase enzymes that initiate RNA destabilization through activation of RNase $\mathrm{L}^{65,66}$. It will be pertinent to examine the susceptibility of Notch1 mRNA transcript under various stress conditions and its impact on the downstream targets. It will be interesting to know if mutated Notch1 allele generate a truncated protein that is still active but has unexpected impact on transcription at the Notch 1 locus or stability of the Notch 1 mRNA transcript. 


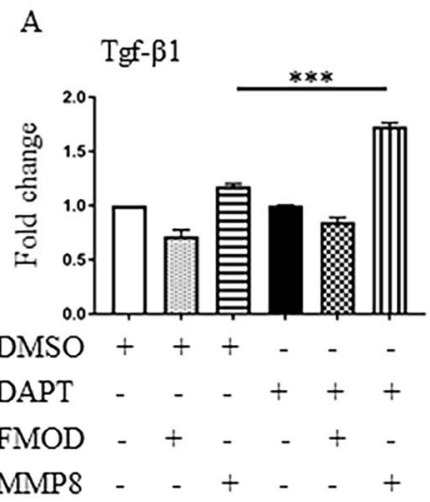

C

Tgf- $\beta R I$

E
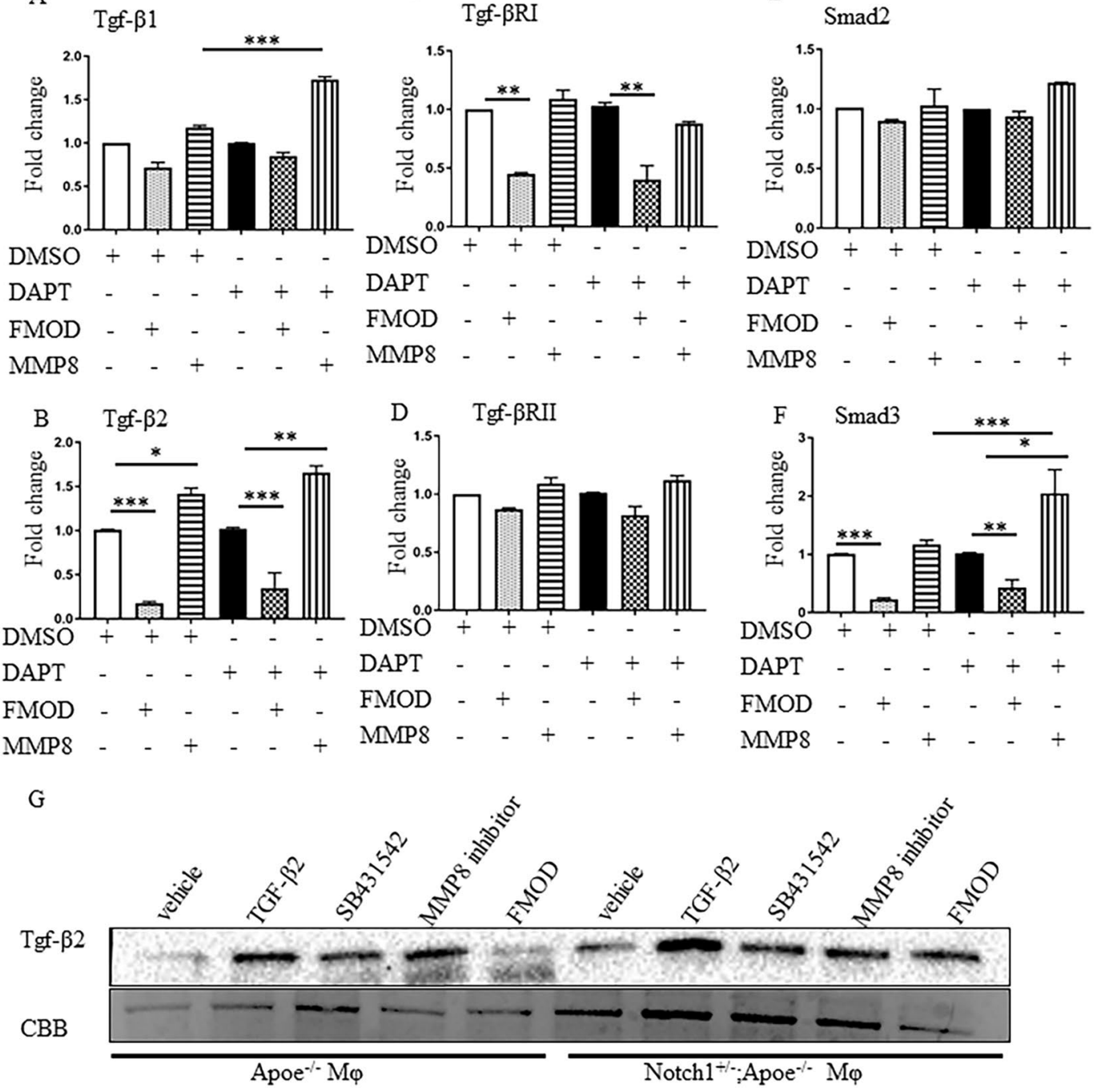

H

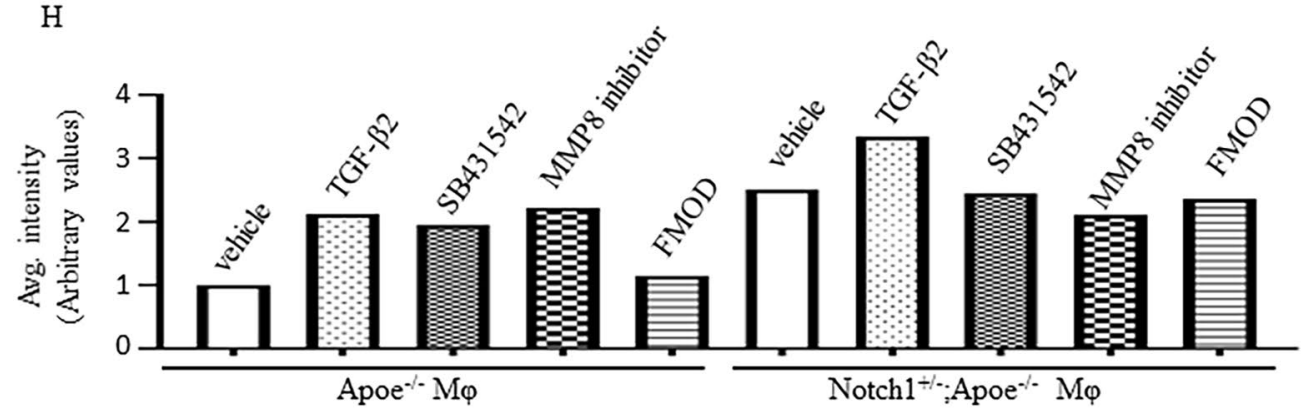

Figure 7. FMOD decreases the expression of Tgf- $\beta 2$ signaling pathway in BMDMs. Gene expression of the members of Tgf- $\beta$ signaling pathway-Tgf- $\beta 1$ (A), Tgf- $\beta 2$ (B), Tgf- $\beta$ RI (C), Tgf- $\beta$ RII (D), Smad2 (E) and Smad 3 (F) was determined using real-time PCR in WT-BMDMs pre-treated with DMSO or DAPT (10 $\mu$ M) for $24 \mathrm{~h}$ followed by treatment with FMOD $(400 \mathrm{ng} / \mathrm{ml})$ or activated-MMP8 $(500 \mathrm{ng} / \mathrm{ml})$ for $24 \mathrm{~h}$. Gene expression was determined using qPCR, normalized to Rpl13a and reported as ratio (mean $\pm \mathrm{SEM}, \mathrm{n}=3$ for each group) to DMSO-C or DAPT-C. (G,H) WB of the media concentrated from Apoe ${ }^{-1-}$ and Notch $1^{+/-} ; A p o e^{-1-}$ BMDMs treated with TGF- $\beta 2$ (human recombinant protein; $5 \mathrm{ng} / \mathrm{ml}$ ), SB431542 (an inhibitor of activin receptor-like kinase; $15 \mathrm{nM})$, MMP8 inhibitor $(10 \mathrm{nM})$ or FMOD $(100 \mathrm{ng} / \mathrm{ml})$ for $24 \mathrm{~h}$ and the quantification. The media was concentrated 50 fold and $20 \mu \mathrm{l}$ volume was loaded for the WB for secreted Tgf- $\beta 2$. Coomassie Brilliant Blue G-250 Dye (CBB) was used to demonstrate equal loading of the media. $* * * P<0.001$, ** $p<0.01, * p<0.05$ (one way ANOVA followed by a Tukey's multiple comparisons test). (WB = Western blot).

Using our novel algorithm approach along with existing knowledge from KEGG pathways and protein-protein interaction networks in mouse, our data provide in silico hypothesis to complement existing hypothesis as well as build new follow-up studies (Fig. 8). Differential effects of Notch deficiency (haploinsufficiency, Notch1-siRNA or 


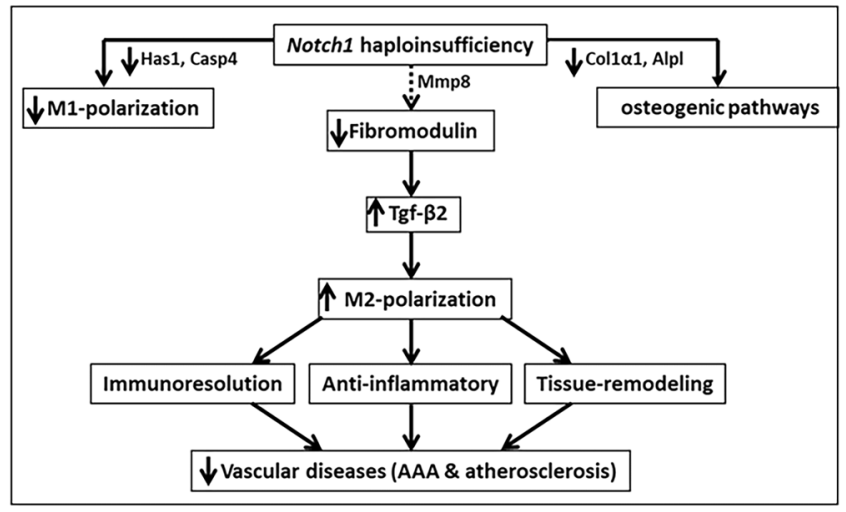

Figure 8. Schematic diagram of the study. The dashed arrows depict the mechanistic pathways suggested by the outcome of RNA-Seq and follow-up experiments in our study.

DAPT) on its downstream effectors may be explained by partial deletion, off-target effects associated with siRNAs or lack of specificity of pharmacological inhibition. Moreover, the basal expression of these genes in the unstimulated and stimulated cells may also affect their differential response. The use of global Notch1 haploinsufficient rather than myeloid-specific Notch1 knockout mice also reflect a limitation in our approach as other cells may influence the functionality and polarization of macrophages. Obviously, more studies will be required to explain these discrepancies. In conclusion, we provide evidence that Notch1 signaling plays a key role in M2-polarization of macrophages through Fmod- dependent regulation of Tgf- $\beta 2$-signaling pathways. These traits of Notch1 haploinsufficiency will open up new avenues to advance research in disease models involving these unique genes. Validation of these unique genes in a mouse model and human pathologies is warranted in the follow-up studies.

\section{Materials and Methods}

Macrophage isolation and treatments, RNA extraction and quality control. Six to eight week old Notch $1^{+1-}$ male and WT female mice (C57BL/6 J background; Jackson Laboratory) were crossbred to generate WT and Notch $1^{+/-}$mice $\left(\mathrm{n}=12\right.$ each). Generation of the C57BL/6 Notch $1^{+/-}$mice has been described previously $^{38}$. Mice were kept on a $12 \mathrm{~h} / 12 \mathrm{~h}$ light/dark cycle with standard chow. Genotyping was performed according to the protocol from Jackson Laboratories (Supplemental Fig. 1A). BMDMs were isolated from six to eight week old $W T$ or Notch $1^{+l-}$ littermates by previously established protocol ${ }^{20,21}$. Briefly, femur and tibia bones were flushed with culture media under aseptic conditions and cells were collected and treated with ACK lysis buffer (Gibco) to lyse RBCs. The remaining bone-marrow derived cells were cultured in ultra-low 6 well tissue culture plates. After $6 \mathrm{~h}$, cells were treated with macrophage colony stimulating factor (M-CSF; $10 \mathrm{ng} / \mathrm{ml}, \mathrm{R} \& \mathrm{D}$ systems) in complete medium (RPMI $1640+10 \%$ human serum $+1 \%$ penicillin streptomycin) with a media change every other day. At day 7, cells were serum starved in 1\% FCS-RPMI for $2 \mathrm{~h}$ followed by stimulation with lipopolysaccharide (LPS; $100 \mathrm{ng} / \mathrm{ml}$, Sigma Aldrich) and interferon- $\gamma$ (IFN- $\gamma ; 20 \mathrm{ng} / \mathrm{ml}$, Biolegend) or IL-4/IL-13 (10 ng/ $\mathrm{ml}$ each, R\&D systems) for $24 \mathrm{~h}$ to polarize bone-marrow derived cells into M1 or M2 states respectively ${ }^{20,21,67}$. For naïve macrophages, cells were treated with vehicle only. For gene expression analysis, media was removed and the cell pellets were mixed with RLT lysis buffer (Qiagen). Total RNA was extracted using the RNeasy kit (Qiagen) following the manufacturers' instructions. Isolated RNA was further processed with DNase treatment and removal reagent (Ambion) to eliminate genomic DNA. The concentration of extracted RNA was measured using a Nanodrop ND1000 to verify that the 260/280 and 260/230 ratios were $\sim 2$.

Samples were then stored at $-80^{\circ} \mathrm{C}$ until shipped to Ocean Ridge Biosciences LLC (Palm Beach Gardens, FL) for quality control (QC) analyses and RNA-Sequencing ${ }^{68}$. The RNA was quantified again by Ocean Ridge using O.D. measurement and assessed for quality on a $1 \%$ agarose $-2 \%$ formaldehyde RNA QC gel (Supplemental Fig. $1 \mathrm{~B})^{68}$. A portion of cDNA was used to confirm the downregulation of Notch1 gene expression and its downstream targets in the Notch $1^{+/-}$BMDMs by qRT-PCR (Supplemental Fig. 1C). The samples were run in triplicate and the fold-change was determined by normalizing CT values against Rpl13a. The primers sequences used in our study are shown in Supplemental Table 3. The read counts in the region of the PCR primers aligning to Notch1 in the WT and Notch $1^{+/-}$BMDMs were analyzed for mapping quality and alignment and RNA degradation (Supplemental Fig. 1D-G).

Library preparation, sequencing and data pre-processing. A total of $1000 \mathrm{ng}$ of DNA-free total RNA was used as the input for a TruSeq Stranded mRNA Library Prep Kit (Illumina Inc., San Diego, CA) to prepare amplified cDNA libraries suitable for sequencing. The quality and size distribution of the amplified libraries were determined using an Agilent 2100 Bioanalyzer High Sensitivity DNA Chip. Libraries were quantified using the KAPA Library Quantification Kit (Kapa Biosystems, Boston, MA). The libraries were pooled at equimolar concentrations and diluted prior to loading onto the flow cell of the Illumina cBot cluster station. The libraries were extended and bridge amplified to create sequence clusters using the Illumina HiSeq PE Cluster Kit v4 and sequenced on an Illumina HiSeq Flow Cell v4 with 50-bp paired-end reads plus index read using the Illumina HiSeq SBS Kit v4. Real time image analysis and base calling were performed on the instrument using the HiSeq 
Sequencing Control Software version 2.2.58. All samples had a minimum of 51,304,689 passed-filter 50 nucleotide paired-end reads. The samples aligned at an average of $87.5 \% \pm 0.5 \%$ (SD) efficiency to the reference genome. The raw fastq files were split into files containing 4,000,000 reads and checked for quality using fastx toolbox ${ }^{69}$. Based on the quality results, the reads were filtered (removing sequences that did not pass Illumina's quality filter) and trimmed of 3 nucleotides at the left end of R1 and 1 nucleotide from the left end of R2.

Sequence alignment, exon and gene level counting, annotation and filtering. Sequence alignment was performed using TopHat v2.1.0 using the Ensembl mouse reference genome release 83 and $\mathrm{mm} 10$ BOWTIE2 GENOME INDEX files from ftp://ftp.ccb.jhu.edu/pub/data/bowtie2_indexes/70-72. For exon and gene level counting Bioconductor easyRNASeq. ${ }^{3}$ v. 2.4.7 package running on R version 3.2.2 platform was used ${ }^{73}$. A binary annotation file (gAnnot_GRCm38.83.rda, see accompanying annotation folder) built using the annotation file generation function of easy RNASeq, was used for this analysis; the annotation version is Ensembl mouse release 83. The easyRNASeq software was downloaded from: http://www.bioconductor.org/packages/release/ bioc/html/easyRNASeq.html.

A Gene Transfer Format (GTF) annotation file for Mus musculus was downloaded from Ensembl Biomart. This file, ensembl_Mus_musculus.GRCm38.83.chr.gtf, contained the current Ensembl Mouse Release 83. Descriptions for each gene in the Ensembl Mouse Release 83 GTF file were downloaded from Biomart and added to the annotation from the GTF file to generate the final file named mart83_export_mmu38-rev_052016.txt. This file contained 708,810 rows, which represent 448,141 unique exons and 46,983 unique genes. The RPKM values were filtered to retain a list of genes with a minimum of approximately 50 mapped reads in one or more samples. The threshold of 50 mapped reads is considered the Reliable Quantification Threshold, since the RPKM values for a gene represented by 50 reads should be reproducible in technical replicates. To avoid reporting large fold changes due to random variation of counts from low abundance mRNA, RPKM values equivalent to a count of $<=10$ reads per gene were replaced with the average RPKM value equivalent to 10 reads/gene across all the samples in the experiment.

WebGestalt analysis and validation by qRT-PCR and Immunostaining. WebGestalt software was utilized for a statistics-based pathway analysis in order to determine the distribution of differentially expressed genes (DEGs) among functional biological pathways ${ }^{74}$. The software compares the relative distribution of genes that met specific significance criteria to the distribution of all detectable genes. Statistical significance in specific pathways is based on an adjusted $p<0.05$ for enrichment of genes meeting the selection criteria, relative to the reference genes. The WebGestalt software was used to query three pathway databases including KEGG, Wiki Pathways, and GO Pathways ${ }^{34,75}$.

For the validation of DEGs, naive macrophages were collected from the BMDMs of WT or Notch1 ${ }^{+/-}$mice (triplicate; pooled from 9 mice each) as detailed earlier ${ }^{20,21}$. Naïve macrophages at day 7 or RAW cells (264.7, a murine monocyte/macrophage cell line, ATCC) were pre-treated with DAPT $(10 \mu \mathrm{M})$ or DMSO for $72 \mathrm{~h}$ prior to incubation with LPS/IFN- $\gamma$ or IL4/IL13 as described ${ }^{76}$. Following treatment, RAW cells and macrophages were washed with cold PBS and RNA extracted using RNAeasy kit (Qiagen). cDNA was synthesized using SuperScript VILO $^{\mathrm{TM}}$ cDNA Synthesis Kit (Invitrogen) and subjected to qRT-PCR by SYBR Green RT-PCR kit (BioRad) using Applied Biosystems 7500 Fast Real-Time PCR or Biorad CFX Connect ${ }^{\mathrm{TM}}$. The samples were run in triplicate and the fold-change was determined by normalizing CT values against Rpl13a. DIF staining of BMDMs was performed using Fmod and Tgf- $\beta 2$ antibodies, nuclei were stained with DAPI. Quantification of DIF was performed using Lionheart FX gen5 software ${ }^{77}$. To determine the stability of Notch $1 \mathrm{mRNA}$, macrophages were treated with Actinomycin D $(20 \mu \mathrm{g} / \mathrm{ml}$, A1410; Sigma) or human recombinant HuR (10 ng/ml, Novus Biologicals) for $24 \mathrm{~h}$ and RNA was extracted using RNAeasy kit (Qiagen).

Transfection of BMDMs and FMOD treatments. Plasmids and siRNA sequences were used for transfecting macrophages. NICD plasmids were obtained from Dr. Lilly's laboratory ${ }^{19,78}$. Predesigned Notch1 (s70698, Invitrogen) siRNA were used with Lipofectamine 3000 (L3000, Invitrogen) and Lipofectamine RNA iMAX (13778, Invitrogen) as explained ${ }^{19,78}$. The cells were plated into 6-well plates with normal growth serum. Two hours prior to transfection, DMEM media without serum and antibiotics were added to the cells. The reagents for transfection were prepared using OptiMEM media (31985-070, Invitrogen). Two different tubes were prepared for each well; one containing the OptiMEM and Lipofectamine P3000 and the other containing OptiMEM, Lipofectamine P3000/RNA iMAX reagent, and either the plasmid $(2 \mu \mathrm{l} / \mu \mathrm{g}$ DNA $)$ or the siRNA for Notch 1 . These two tubes were then combined and the mixture was incubated for 5 minutes at room temperature. This mixture was then added directly onto the cells containing the DMEM serum-free and antibiotic-free media. The media was changed four to six hours after transfection with normal growth medium. RNA was extracted $48 \mathrm{~h}$ post transfection and subjected to qRT-PCR. To determine the effect of FMOD on M1 and M2 genes, macrophages were pre-treated in serum-free RPMI culture medium followed by treatment with recombinant human FMOD Protein (400 ng/ml; Ab152392, Abcam) for $24 \mathrm{~h}$.

FMOD and MMP8 treatments, protein isolation, Western blot and Quantification. In a separate experiment, macrophages were pre-treated overnight with DMSO or DAPT $(10 \mu \mathrm{M})$ in serum-free RPMI culture medium followed by treatment with either Recombinant Human FMOD Protein (400 ng/ml; Ab152392, Abcam) or activated-MMP8 ( $400 \mathrm{ng} / \mathrm{ml}$, Fisher) for $24 \mathrm{~h}$. MMP8 was activated using p-aminophenylmercuric acetate (APMA) following a standard protocol. RNA was extracted from these cells for gene-expression study. In some wells, BMDMs from WT or Notch $1^{+/-}$were treated with either TGF- 32 (human recombinant protein; $5 \mathrm{ng} / \mathrm{ml}$, Fisher), TGF $\beta$ receptor kinase inhibitor (SB-431542; $15 \mathrm{nM}$, Tocris Biosciences), FMOD (100 ng/ml) or MMP8 inhibitor $\left(400 \mathrm{ng} / \mathrm{ml}\right.$, Fisher) for $24 \mathrm{~h}$. The media was concentrated using Amicon ${ }^{\circledR}$ Ultra-4 Centrifugal Filter 
Units (3 KDa, Millipore) to $100 \mu \mathrm{l}$ (1:50) and Western blot was performed to detect secreted Tgf- $\beta 2$ (as a measure of active-Tgf- $\beta$ signaling) using a standard protocol ${ }^{76,79-81}$.

Total proteins were extracted from the cells with RIPA buffer supplemented with protease and phosphatase inhibitor cocktails (Roche). After homogenization, proteins concentrations were measured using a Pierce ${ }^{\text {tm }}$ BCA Protein Assay Kit (Thremo-Fisher) and $10 \mu \mathrm{g}$ of protein was subsequently loaded onto a $10 \%$ SDS-polyacrylamide gel and transferred to PVDF membrane using standard protocols ${ }^{19,80,82}$. The membranes were probed for Fmod (Ab81443, Abcam), TGF-32 (Ab36495, Abcam), MMP8 (Ab81286, Abcam) and NICD (Ab8925, Abcam) following standard protocols ${ }^{76,79-81}$. GAPDH (NB300-221, Novus Biologicals) and Coomassie Blue staining (Bio-Rad) were used as the internal loading controls for the cells and media respectively. Western blots were quantified using Image J software in three replicates and representative blot is shown ${ }^{83}$.

Isolation of peritoneal macrophages and Co-Immunoprecipitation. Peritoneal macrophages from WT and Notch $1^{+/-}$mice were isolated three days after thioglycollate stimulation as described previously ${ }^{80}$. The anti-Fmod antibody $(100 \mu \mathrm{g})$ were coupled with dynabeads $(5 \mathrm{mg})$ overnight following the recommended protocol (14321D, life technologies). The cell lysates derived from WT and $N o t c h 1^{+1-}$ peritoneal macrophages were pulled down with FMOD antibody. The Co-IP products were washed three times with PBS. After the final wash, the dynabeads were re-suspended in $40 \mu \mathrm{L}$ of sample buffer were probed for TGF- $\beta 2$, Fmod and NICD by Western blot.

Study Approval. All animal-related experiments were approved by the Institutional Animal Care and Use Committee at the Research Institute at Nationwide Children's Hospital (Columbus, $\mathrm{OH}$ ) and at the University of Missouri (Columbia, MO). All the methods were performed in accordance with the relevant guidelines and regulations. The IF and Western blot images represent the original data and conform to community standards.

KBCommons database for mouse. The analyzed gene expression datasets and gene modules can be accessed interactively via mouseKB in KBCommons (http://kbcommons.org/system/browse/diff_exp/ MusMusculus), a comprehensive framework fully equipped with database and informatics tools for multi-omics data analysis. It provides a set of visualization and analytical tools such as differential expression analysis and gene card pages and provides data in the form of tabs for Gene lists, Venn diagram, Volcano plot, Function Analysis, Pathway Analysis and Gene modules. The Function Analysis tab provides a functional annotation pie chart and particular annotation lists for gene families and PFAM domains ${ }^{84}$. The Pathway Analysis tab retrieves the $\mathrm{KEGG}^{8}$ pathway mapping for the genes ${ }^{34}$. The Gene module tab provides weighted correlation network analysis (WGCNA) which identifies the correlation patterns among genes and forms modules based on that analysis ${ }^{31}$.

Statistical analysis. Pearson's correlation coefficient using $\log _{2}$ and 2-way ANOVA using replicate pairs was performed on the RPKM data for the 20,375 detectable mouse genes to examine the effect of cell type ( $W T$ and Notch $1^{+/-}$) or treatments (Control, LPS/IFN- $\gamma$, and IL4/IL13) as well as their interactions on gene expression. Tukey's tests were performed to determine the effects of treatment against control within each cell type, and the effect of cell type at each treatment. Fold changes were calculated for the same comparisons by comparing the mean values from both groups. If the mean of both groups under comparison were below the Detection Threshold (10 reads/ gene), "NA" was reported. All statistical analyses were performed using R version 3.2.2 statistical computing software. For the real-time qRT-PCR quantification, we performed the Kruskal-Wallis test using a non-parametric method for the overall significance of the data and ordinary ANOVA followed by a Turkey's multiple comparisons test using GraphPad Prism version 5.0. The additional datasets generated during in the current study are available from the corresponding author on reasonable request.

\section{Data Availability}

For the original RNASeq data files, contact Dr. Chetan Hans. For further information about bioinformatics, contact Trupti Joshi. The analyzed gene expression datasets and gene modules can be accessed interactively via mouseKB in KBCommons (http://kbcommons.org/system/browse/diff_exp/MusMusculus), a comprehensive framework fully equipped with database and informatics tools for multi-omics data analysis.

\section{References}

1. El-Gabalawy, H., Guenther, L. C. \& Bernstein, C. N. Epidemiology of immune-mediated inflammatory diseases: incidence, prevalence, natural history, and comorbidities. J Rheumatol Suppl 85, 2-10, https://doi.org/10.3899/jrheum.091461 (2010).

2. Motwani, M. P. \& Gilroy, D. W. Macrophage development and polarization in chronic inflammation. Semin Immunol 27, 257-266, https://doi.org/10.1016/j.smim.2015.07.002 (2015).

3. Prud'homme, G. J. Pathobiology of transforming growth factor beta in cancer, fibrosis and immunologic disease, and therapeutic considerations. Lab Invest 87, 1077-1091, https://doi.org/10.1038/labinvest.3700669 (2007).

4. Vujosevic, S. \& Simo, R. Local and Systemic Inflammatory Biomarkers of Diabetic Retinopathy: An Integrative Approach. Invest Ophthalmol Vis Sci 58, BIO68-BIO75, https://doi.org/10.1167/iovs.17-21769 (2017).

5. Sica, A., Erreni, M., Allavena, P. \& Porta, C. Macrophage polarization in pathology. Cell Mol Life Sci 72, 4111-4126, https://doi. org/10.1007/s00018-015-1995-y (2015).

6. Gaffney, L., Warren, P., Wrona, E. A., Fisher, M. B. \& Freytes, D. O. In Macrophages: Origin, Functions and Biointervention (ed Malgorzata Kloc) 245-271 (Springer International Publishing, 2017).

7. Valledor, A. F., Comalada, M., Santamaría-Babi, L. F., Lloberas, J. \& Celada, A. In Advances in Immunology Vol. 108 (eds Frederick W. Alt et al.) 1-20 (Academic Press, 2010).

8. Chinetti-Gbaguidi, G. \& Staels, B. Macrophage polarization in metabolic disorders: functions and regulation. Curr Opin Lipidol 22, 365-372, https://doi.org/10.1097/MOL.0b013e32834a77b4 (2011).

9. Xu, L., Kitade, H., Ni, Y. \& Ota, T. Roles of Chemokines and Chemokine Receptors in Obesity-Associated Insulin Resistance and Nonalcoholic Fatty Liver Disease. Biomolecules 5, 1563-1579, https://doi.org/10.3390/biom5031563 (2015).

10. Novak, M. L. \& Koh, T. J. Phenotypic transitions of macrophages orchestrate tissue repair. Am J Pathol 183, 1352-1363, https://doi. org/10.1016/j.ajpath.2013.06.034 (2013). 
11. Zhou, D. et al. Macrophage polarization and function: new prospects for fibrotic disease. Immunol Cell Biol 95, 864-869, https://doi. org/10.1038/icb.2017.64 (2017).

12. Vergadi, E., Ieronymaki, E., Lyroni, K., Vaporidi, K. \& Tsatsanis, C. Akt Signaling Pathway in Macrophage Activation and M1/M2 Polarization. J Immunol 198, 1006-1014, https://doi.org/10.4049/jimmunol.1601515 (2017).

13. Murray, P. J. Macrophage Polarization. Annual Review of Physiology 79, 541-566, https://doi.org/10.1146/annurevphysiol-022516-034339 (2017).

14. Jablonski, K. A. et al. Novel Markers to Delineate Murine M1 and M2 Macrophages. PloS one 10, e0145342, https://doi.org/10.1371/ journal.pone.0145342 (2015).

15. Martinez, F. O. \& Gordon, S. The M1 and M2 paradigm of macrophage activation: time for reassessment. F1000Prime Reports 6, 13, https://doi.org/10.12703/P6-13 (2014).

16. Murray, P. J. et al. Macrophage activation and polarization: nomenclature and experimental guidelines. Immunity 41, 14-20, https:// doi.org/10.1016/j.immuni.2014.06.008 (2014).

17. Nakano, T., Fukuda, D., Koga, J. \& Aikawa, M. Delta-Like Ligand 4-Notch Signaling in Macrophage Activation. Arterioscler Thromb Vasc Biol 36, 2038-2047, https://doi.org/10.1161/ATVBAHA.116.306926 (2016).

18. Xu, J., Chi, F. \& Tsukamoto, H. Notch signaling and M1 macrophage activation in obesity-alcohol synergism. Clin Res Hepatol Gastroenterol 39(Suppl 1), S24-28, https://doi.org/10.1016/j.clinre.2015.05.016 (2015).

19. Sachdeva, J. et al. Smooth muscle cell-specific Notch 1 haploinsufficiency restricts the progression of abdominal aortic aneurysm by modulating CTGF expression. PloS one 12, e0178538, https://doi.org/10.1371/journal.pone.0178538 (2017).

20. Cheng, J., Koenig, S. N., Kuivaniemi, H. S., Garg, V. \& Hans, C. P. Pharmacological inhibitor of notch signaling stabilizes the progression of small abdominal aortic aneurysm in a mouse model. J Am Heart Assoc 3, e001064, https://doi.org/10.1161/ JAHA.114.001064 (2014).

21. Hans, C. P. et al. Inhibition of Notch1 signaling reduces abdominal aortic aneurysm in mice by attenuating macrophage-mediated inflammation. Arterioscler Thromb Vasc Biol 32, 3012-3023, https://doi.org/10.1161/ATVBAHA.112.254219 (2012).

22. Singla, D. K., Wang, J. \& Singla, R. Primary human monocytes differentiate into M2 macrophages and involve Notch-1 pathway. Can J Physiol Pharmacol 95, 288-294, https://doi.org/10.1139/cjpp-2016-0319 (2017).

23. Xu, H. et al. Notch-RBP-J signaling regulates the transcription factor IRF8 to promote inflammatory macrophage polarization. Nat Immunol 13, 642-650, https://doi.org/10.1038/ni.2304 (2012).

24. Zhou, D. et al. Macrophage polarization and function with emphasis on the evolving roles of coordinated regulation of cellular signaling pathways. Cell Signal 26, 192-197, https://doi.org/10.1016/j.cellsig.2013.11.004 (2014).

25. Hu, Y.-Y., Zheng, M.-h., Zhang, R., Liang, Y.-M. \& Han, H. In Notch Signaling in Embryology and Cancer Vol. 727 Advances in Experimental Medicine and Biology (eds Jörg Reichrath \& Sandra Reichrath) Ch. 14, 186-198 (Springer US, 2012).

26. Gridley, T. Notch signaling in the vasculature. Curr Top Dev Biol 92, 277-309, https://doi.org/10.1016/S0070-2153(10)92009-7 (2010).

27. Bray, S. J. Notch signalling: a simple pathway becomes complex. Nat Rev Mol Cell Biol 7, 678-689, https://doi.org/10.1038/nrm2009 (2006).

28. Quillard, T. \& Charreau, B. Impact of notch signaling on inflammatory responses in cardiovascular disorders. Int J Mol Sci 14, 6863-6888, https://doi.org/10.3390/ijms14046863 (2013).

29. Zou, S. et al. Notch signaling in descending thoracic aortic aneurysm and dissection. PloS one 7, e52833, https://doi.org/10.1371/ journal.pone.0052833 (2012).

30. de Hoon, M. J., Imoto, S., Nolan, J. \& Miyano, S. Open source clustering software. Bioinformatics 20, 1453-1454, https://doi. org/10.1093/bioinformatics/bth078 (2004).

31. Langfelder, P. \& Horvath, S. WGCNA: an R package for weighted correlation network analysis. BMC Bioinformatics 9, 559, https:// doi.org/10.1186/1471-2105-9-559 (2008).

32. Sharov, A. A., Dudekula, D. B. \& Ko, M. S. A web-based tool for principal component and significance analysis of microarray data. Bioinformatics 21, 2548-2549, https://doi.org/10.1093/bioinformatics/bti343 (2005).

33. Ashburner, M. et al. Gene ontology: tool for the unification of biology. The Gene Ontology Consortium. Nat Genet 25, 25-29, https://doi.org/10.1038/75556 (2000).

34. Kanehisa, M., Sato, Y., Kawashima, M., Furumichi, M. \& Tanabe, M. KEGG as a reference resource for gene and protein annotation. Nucleic Acids Res 44, D457-462, https://doi.org/10.1093/nar/gkv1070 (2016).

35. Cisneros, E., Latasa, M. J., García-Flores, M. \& Frade, J. M. Instability of Notch1 and Delta1 mRNAs and reduced Notch activity in vertebrate neuroepithelial cells undergoing S-phase. Molecular and Cellular Neuroscience 37, 820-831, https://doi.org/10.1016/j. mcn.2008.01.011 (2008)

36. Houseley, J. \& Tollervey, D. The Many Pathways of RNA Degradation. Cell 136, 763-776, https://doi.org/10.1016/j.cell.2009.01.019 (2009).

37. Wang, Z. et al. Stabilization of Notch1 by the Hsp90 Chaperone is Crucial for T-Cell Leukemogenesis. Clinical Cancer Research 23, 3834 (2017).

38. Conlon, R. A., Reaume, A. G. \& Rossant, J. Notch1 Is Required for the Coordinate Segmentation of Somites. Development 121, 1533-1545 (1995).

39. Wen, G. et al. A Novel Role of Matrix Metalloproteinase-8 in Macrophage Differentiation and Polarization. J Biol Chem 290, 19158-19172, https://doi.org/10.1074/jbc.M114.634022 (2015).

40. Shami, A. et al. Fibromodulin deficiency reduces low-density lipoprotein accumulation in atherosclerotic plaques in apolipoprotein E-null mice. Arterioscler Thromb Vasc Biol 33, 354-361, https://doi.org/10.1161/ATVBAHA.112.300723 (2013).

41. Awad, F. et al. Impact of human monocyte and macrophage polarization on NLR expression and NLRP3 inflammasome activation. PloS one 12, e0175336, https://doi.org/10.1371/journal.pone.0175336 (2017).

42. Kim, E. Y. \& Kim, B. C. Lipopolysaccharide inhibits transforming growth factor-beta1-stimulated Smad6 expression by inducing phosphorylation of the linker region of Smad3 through a TLR4-IRAK1-ERK1/2 pathway. FEBS Lett 585, 779-785, https://doi. org/10.1016/j.febslet.2011.01.044 (2011).

43. Mitchell, K. et al. LPS antagonism of TGF-beta signaling results in prolonged survival and activation of rat primary microglia. $J$ Neurochem 129, 155-168, https://doi.org/10.1111/jnc.12612 (2014).

44. Jan, A. T., Lee, E. J. \& Choi, I. Fibromodulin: A regulatory molecule maintaining cellular architecture for normal cellular function. Int J Biochem Cell Biol 80, 66-70, https://doi.org/10.1016/j.biocel.2016.09.023 (2016).

45. Yang, M. et al. Osteoclast stimulatory transmembrane protein (OC-STAMP), a novel protein induced by RANKL that promotes osteoclast differentiation. J Cell Physiol 215, 497-505, https://doi.org/10.1002/jcp.21331 (2008).

46. Ito, R. et al. Osteosclerosis and inhibition of human hematopoiesis in NOG mice expressing human Delta-like 1 in osteoblasts. Exp Hematol 40, 953-963 e953, https://doi.org/10.1016/j.exphem.2012.07.002 (2012).

47. Nakajima, K. et al. Galectin-3 inhibits osteoblast differentiation through notch signaling. Neoplasia 16, 939-949, https://doi. org/10.1016/j.neo.2014.09.005 (2014).

48. Hu, M. et al. Notch signaling regulates collalpha1 and collalpha2 expression in airway fibroblasts. Exp Biol Med (Maywood) 239, 1589-1596, https://doi.org/10.1177/1535370214538919 (2014).

49. Wilkinson, T. S., Bressler, S. L., Evanko, S. P., Braun, K. R. \& Wight, T. N. Overexpression of hyaluronan synthases alters vascular smooth muscle cell phenotype and promotes monocyte adhesion. J Cell Physiol 206, 378-385, https://doi.org/10.1002/jcp.20468 (2006). 
50. Woodruff, P. G. et al. A distinctive alveolar macrophage activation state induced by cigarette smoking. Am J Respir Crit Care Med 172, 1383-1392, https://doi.org/10.1164/rccm.200505-686OC (2005).

51. John, A. E. et al. Loss of epithelial Gq and G11 signaling inhibits TGFbeta production but promotes IL-33-mediated macrophage polarization and emphysema. Sci Signal 9, ra104, https://doi.org/10.1126/scisignal.aad5568 (2016).

52. Abe, Y. et al. TIM-4 has dual function in the induction and effector phases of murine arthritis. J Immunol 191, 4562-4572, https:// doi.org/10.4049/jimmunol.1203035 (2013).

53. Lakshmanan, U. \& Porter, A. G. Caspase-4 Interacts with TNF Receptor-Associated Factor 6 and Mediates LipopolysaccharideInduced NF- B-Dependent Production of IL-8 and CC Chemokine Ligand 4 (Macrophage-Inflammatory Protein-1). The Journal of Immunology 179, 8480-8490, https://doi.org/10.4049/jimmunol.179.12.8480 (2007).

54. Kushiyama, T. et al. Alteration in the phenotype of macrophages in the repair of renal interstitial fibrosis in mice. Nephrology (Carlton) 16, 522-535, https://doi.org/10.1111/j.1440-1797.2010.01439.x (2011).

55. Riquelme, P. et al. Dhrs9 Is a Specific and Stable Marker of Human Regulatory Macrophages. Transpl Int 30, 27-27 (2017).

56. Poczobutt, J. M. et al. Expression Profiling of Macrophages Reveals Multiple Populations with Distinct Biological Roles in an Immunocompetent Orthotopic Model of Lung Cancer. J Immunol 196, 2847-2859, https://doi.org/10.4049/jimmunol.1502364 (2016).

57. Romano, G., Veneziano, D., Acunzo, M. \& Croce, C. M. Small non-coding RNA and cancer. Carcinogenesis 38, 485-491, https://doi. org/10.1093/carcin/bgx026 (2017)

58. Miyamoto, H. et al. An essential role for STAT6-STAT1 protein signaling in promoting macrophage cell-cell fusion. J Biol Chem 287, 32479-32484, https://doi.org/10.1074/jbc.M112.358226 (2012).

59. Chinetti-Gbaguidi, G. et al. Human Alternative Macrophages Populate Calcified Areas of Atherosclerotic Lesions and Display Impaired RANKL-Induced Osteoclastic Bone Resorption Activity. Circulation research 121, 19-30, https://doi.org/10.1161/ CIRCRESAHA.116.310262 (2017).

60. Calve, S., Isaac, J., Gumucio, J. P. \& Mendias, C. L. Hyaluronic acid, HAS1, and HAS2 are significantly upregulated during muscle hypertrophy. American journal of physiology. Cell physiology 303, C577-588, https://doi.org/10.1152/ajpcell.00057.2012 (2012).

61. Dabritz, J. et al. Reprogramming of monocytes by GM-CSF contributes to regulatory immune functions during intestinal inflammation. J Immunol 194, 2424-2438, https://doi.org/10.4049/jimmunol.1401482 (2015).

62. Kim, M.-Y. et al. Regulation of Notch1 signaling by the APP intracellular domain facilitates degradation of the Notch1 intracellular domain and RBP-Jk. Journal of cell science 124, 1831 (2011).

63. Lim, J., Lee, K.-m, Shim, J. \& Shin, I. CD24 regulates stemness and the epithelial to mesenchymal transition through modulation of Notch1 mRNA stability by p38MAPK. Archives of Biochemistry and Biophysics 558, 120-126, https://doi.org/10.1016/j. abb.2014.06.022 (2014).

64. McGill, M. A., Dho, S. E., Weinmaster, G. \& McGlade, C. J. Numb Regulates Post-endocytic Trafficking and Degradation of Notch1. The Journal of Biological Chemistry 284, 26427-26438, https://doi.org/10.1074/jbc.M109.014845 (2009).

65. Kristiansen, H., Gad, H. H., Eskildsen-Larsen, S., Despres, P. \& Hartmann, R. The oligoadenylate synthetase family: an ancient protein family with multiple antiviral activities. J Interferon Cytokine Res 31, 41-47, https://doi.org/10.1089/jir.2010.0107 (2011).

66. Choi, U. Y., Kang, J. S., Hwang, Y. S. \& Kim, Y. J. Oligoadenylate synthase-like (OASL) proteins: dual functions and associations with diseases. Exp Mol Med 47, e144, https://doi.org/10.1038/emm.2014.110 (2015).

67. Weischenfeldt, J. \& Porse, B. Bone Marrow-Derived Macrophages (BMM): Isolation and Applications. CSH Protoc 2008, pdb prot5080, https://doi.org/10.1101/pdb.prot5080 (2008).

68. Barnette, D. N., VandeKopple, M., Wu, Y., Willoughby, D. A. \& Lincoln, J. RNA-seq analysis to identify novel roles of scleraxis during embryonic mouse heart valve remodeling. PloS one 9, e101425, https://doi.org/10.1371/journal.pone.0101425 (2014).

69. Lab, H.

70. Trapnell, C., Pachter, L. \& Salzberg, S. L. TopHat: discovering splice junctions with RNA-Seq. Bioinformatics 25, 1105-1111, https:// doi.org/10.1093/bioinformatics/btp120 (2009).

71. Langmead, B., Trapnell, C., Pop, M. \& Salzberg, S. L. Ultrafast and memory-efficient alignment of short DNA sequences to the human genome. Genome Biol 10, R25, https://doi.org/10.1186/gb-2009-10-3-r25 (2009).

72. Kim, D. \& Salzberg, S. L. TopHat-Fusion: an algorithm for discovery of novel fusion transcripts. Genome Biol 12, R72, https://doi. org/10.1186/gb-2011-12-8-r72 (2011)

73. Delhomme, N., Padioleau, I., Furlong, E. E. \& Steinmetz, L. M. easyRNASeq: a bioconductor package for processing RNA-Seq data. Bioinformatics 28, 2532-2533, https://doi.org/10.1093/bioinformatics/bts477 (2012).

74. Wang, J., Duncan, D., Shi, Z. \& Zhang, B. WEB-based GEne SeT AnaLysis Toolkit (WebGestalt): update 2013. Nucleic Acids Res 41, W77-83, https://doi.org/10.1093/nar/gkt439 (2013).

75. Gene Ontology, C. Gene Ontology Consortium: going forward. Nucleic Acids Res 43, D1049-1056, https://doi.org/10.1093/nar/ gku1179 (2015).

76. Acharya, A. et al. Inhibitory role of Notch1 in calcific aortic valve disease. PloS one 6, e27743, https://doi.org/10.1371/journal. pone.0027743 (2011).

77. Kalidhindi, R. S. R. et al. In D58. Airways Hyperresponsiveness: Novel Mechanisms and Targets American Thoracic Society International Conference Abstracts A7266-A7266 (American Thoracic Society, 2018).

78. Lin, C. H. \& Lilly, B. Notch signaling governs phenotypic modulation of smooth muscle cells. Vascul Pharmacol 63, 88-96, https:// doi.org/10.1016/j.vph.2014.09.004 (2014).

79. Bosse, K. et al. Endothelial nitric oxide signaling regulates Notchl in aortic valve disease. J Mol Cell Cardiol 60, 27-35, https://doi. org/10.1016/j.yjmcc.2013.04.001 (2013).

80. Oumouna-Benachour, K. et al. Poly(ADP-ribose) polymerase inhibition reduces atherosclerotic plaque size and promotes factors of plaque stability in apolipoprotein E-deficient mice: effects on macrophage recruitment, nuclear factor-kappaB nuclear translocation, and foam cell death. Circulation 115, 2442-2450, https://doi.org/10.1161/CIRCULATIONAHA.106.668756 (2007).

81. Zerfaoui, M. et al. Nuclear translocation of p65 NF-kappaB is sufficient for VCAM-1, but not ICAM-1, expression in TNFstimulated smooth muscle cells: Differential requirement for PARP-1 expression and interaction. Cell Signal 20, 186-194, https:// doi.org/10.1016/j.cellsig.2007.10.007 (2008).

82. Hans, C. P. et al. Thieno[2,3-c]isoquinolin-5-one, a potent poly(ADP-ribose) polymerase inhibitor, promotes atherosclerotic plaque regression in high-fat diet-fed apolipoprotein E-deficient mice: effects on inflammatory markers and lipid content. J Pharmacol Exp Ther 329, 150-158, https://doi.org/10.1124/jpet.108.145938 (2009).

83. Schneider, C. A., Rasband, W. S. \& Eliceiri, K. W. NIH Image to ImageJ: 25 years of image analysis. Nat Methods 9, 671-675 (2012). 84. Punta, M. et al. The Pfam protein families database. Nucleic Acids Res 40, D290-301, https://doi.org/10.1093/nar/gkr1065 (2012).

\section{Acknowledgements}

The authors thank Ocean Ridge Biosciences for carrying out the RNA-Seq analysis. Initial part of this study related to RNA-Seq data was performed at The Research Institute of Nationwide Children's Hospital, Columbus $\mathrm{OH}$. The validations and subsequent experiments were performed at the Dalton Cardiovascular Research Center, University of Missouri. This work was supported by R01 (HL124155) and funding from the Research Institute at Nationwide Children's Hospital and University of Missouri to CPH. 


\section{Author Contributions}

C.P.H.- designing research studies, conducting experiments, acquiring data, analyzing data, providing reagents, and writing the manuscript, N.S., R.D. and A.M.- conducting experiments, acquiring data, analyzing data, S.S., S.Z. and Y.J.- analyzing bioinformatics data, T.J.- acquiring data, analyzing data, and writing the manuscript.

\section{Additional Information}

Supplementary information accompanies this paper at https://doi.org/10.1038/s41598-019-44266-4.

Competing Interests: The authors declare no competing interests.

Publisher's note: Springer Nature remains neutral with regard to jurisdictional claims in published maps and institutional affiliations.

(c) (i) Open Access This article is licensed under a Creative Commons Attribution 4.0 International

License, which permits use, sharing, adaptation, distribution and reproduction in any medium or format, as long as you give appropriate credit to the original author(s) and the source, provide a link to the Creative Commons license, and indicate if changes were made. The images or other third party material in this article are included in the article's Creative Commons license, unless indicated otherwise in a credit line to the material. If material is not included in the article's Creative Commons license and your intended use is not permitted by statutory regulation or exceeds the permitted use, you will need to obtain permission directly from the copyright holder. To view a copy of this license, visit http://creativecommons.org/licenses/by/4.0/.

(c) The Author(s) 2019 